\title{
Economic Fluctuations in Central and Eastern Europe. The Facts ${ }^{*}$
}

\author{
PÉTER BENCZÚR ${ }^{\dagger}$ \\ National Bank of Hungary and \\ Central European University
}

\author{
AtTila RÁTFAI ${ }^{*}$ \\ Central European University
}

March 17, 2004

\begin{abstract}
We carry out a detailed analysis of quarterly frequency dynamics in major macroeconomic aggregates in twelve countries of Central and Eastern Europe. The facts we document include the variability and persistence in and the co-movement among output and other major real and nominal variables. Patterns in cyclicality and persistence are in general in line with evidence from other countries. Output is more volatile in transition economies than in industrial countries. Its components are also more volatile, and their cyclical patterns and persistence are similar to that of industrial countries. The same applies to employment, real wages and productivity, emphasizing the role of real shocks. Employment is coincidental or leading. Private sector credit shows a strong cyclicality, with an ambiguous sign. Monetary aggregates are mostly procyclical, while velocities are countercyclical. The price level tends to be countercyclical, and highly volatile. The cyclicality of inflation is unclear, and its relative volatility is low. Real exchange rates tend to be countercyclical.
\end{abstract}

Key words: business cycle facts, Central and Eastern Europe

JEL Classification: E32

\footnotetext{
* Preliminary. Please do not quote. We thank Cosmin Ilut, Roman Horvath, Reimo Juks, Sorina Vaju and Robertas Zubrickas for excellent research assistance. Paul Wachtel, seminar participants at CEU, the 2003 GDN Meeting in Prague added helpful comments. We thank GDN and CEU for financial support.

${ }^{\dagger}$ Research Department, National Bank of Hungary, Szabadsag ter 8/9, Budapest 1054, Hungary, Email: benczurp@mnb.hu

* Department of Economics, Central European University, Nador u 9, Budapest 1051, Hungary, Email: ratfaia@ceu.hu
} 
The pure notion of the business cycle is a novelty for most policymakers and citizens in the post-socialist countries of Central and Eastern European (CEE). Though economic fluctuations have been severely mixed with the transition bust and boom, it seems to be evident by now that these economies are also subject to ups and downs, regardless of the initial transition shock and the following catch-up process.

The current project is part of a large branch of international macroeconomics, aimed at documenting within- and cross-country empirical regularities about macroeconomic fluctuations. Our main goal is to document facts of economic fluctuations in twelve CEE countries over the decade long period of economic transition, arguably the largest possible panel of data in terms of time frame and country coverage. Besides that the results are expected to serve as factual bases in models of international business cycles, they are valuable tools in the design of stabilization and adjustment policies as well. Documenting the relative cyclical movements of major macro variables can help policymakers identify the most important targets, instruments and the mechanism of counter-cyclical policies in these countries. In a monetary union, such as the one most countries we investigate is set to join to in the coming year, the EMU, since monetary policy is common, regional differences in cycles are likely to be the mainly determined by local fiscal policy. Depending on similarities and differences compared to developed economies, our results can then allow one to better judge how much of the general "smoothing" policies should be adopted, and how much "regional flavor" is needed. Finally, while our exploration of basic facts is not driven by a particular model, the evidence we compile is meant to inform theories of open economy business cycles.

We seek to answer the following specific questions.

- Is there already a common pattern to document in CEE business cycle fluctuations?

- Can particular historical episodes in 1990s be explained through the lenses of business cycle analysis?

- Are the findings robust to alternative filtering procedures, or data periods? Can we obtain any robust pre-transition results?

- Are there important similarities and differences in the behavior of macroeconomic aggregates relative to developed countries, or other emerging market regions?

- Can we group CEE countries according to their cyclical patterns? Can we identify certain country characteristics, such as exchange rate regime, government size, openness in goods and financial markets that influence and explain these differences? 
- In the process of joining the European institutions such as the EU and the EMU, can policy-makers treat CEE countries as a relatively homogeneous group? Or rather these economies fundamentally differ from each other, so they need to be considered on an individual basis?

To address these issues, we conduct a detailed unconditional analysis of quarterly frequency dynamics in major macroeconomic aggregates in individual CEE countries. Despite their similarity, CEE economies are characterized by a significant amount of variation in the strength of trading ties to EU, policy arrangements, and country size. By examining macroeconomic data in a large group of countries with similar, still somewhat diverse history, we are seeking to establish stylized facts that highlight regularities that are more general than pure country-specific effects, and point to insights potentially useful for economic theory. We also shed some light on whether basic business cycle regularities in CEE countries are systematically different from those in the G7 group or other European and developing countries. ${ }^{1}$

The business cycle component of fluctuations in macroeconomic variables is defined as the deviation from a trend. As no de-trending procedure is free of criticism, we employ three alternative de-trending procedures, such as Hodrick-Prescott (H-P) filtering, log first differencing, and fitting a quadratic time polynomial in obtaining the cyclical component of macroeconomic variables. While our empirical approach places no constraint on the joint determination of the variables of interest, the transformation of data, the selection of statistics and the interpretation of results are all guided by economic theory. As standard in modern business cycle analysis since the seminal work of Lucas (1977), the most important themes we address include the variability and persistence in and the co-movement among output and other fundamental real and nominal variables. We seek to uncover if de-trended variables move the same direction (procyclical), the opposite direction (countercyclical) or are unrelated to (acyclical) output. We also examine the correlation of variables with de-trended output and the absolute and relative volatility of the variables involved. Finally, we document phase shifts in the variables, i.e. if they lead or lag the cycle, or synchronous (coincidental) with it.

This enterprise requires us to overcome a major hurdle, assembling a data set of quarterly frequency macroeconomic variables in transition economies. Dictated mainly by data availability at the quarterly frequency, the countries examined are Bulgaria, Croatia, the Czech Republic, Estonia, Hungary, Latvia, Lithuania, Poland, Romania, Russia, Slovakia and

\footnotetext{
${ }^{1}$ In a companion paper, Benczúr and Rátfai (2004) give a detailed survey of the international evidence.
} 
Slovenia. ${ }^{2}$ The sample period starts at the beginning of the 1990 s and spans over a period of about 10 years, typically from 1993:1 through 2002:4. The variables collected include output (industrial production and GDP), measures of the price level (and inflation), components of aggregate demand (consumption, investment, government consumption, exports, imports), wages, employment, productivity, exchange rates, credit and monetary aggregates. In addition to national sources including central banks and statistical offices, the final sample is compiled through the WIIW dataset, the Emerging Market Database, the EIU data, and the IMF's IFS tapes.

The rest of this paper is organized as follows. After providing a brief overview of previous related empirical work in Section 2, Section 3 reports in detail on the data set we assembled. Section 4 discusses the findings, while Section 5 concludes.

2

\section{RELATED LITERATURE}

It is only a short while ago, since efforts to systematically document stylized facts of quarterly frequency aggregate fluctuations started to accelerate. The classic study examining the cyclical properties of a number of H-P filtered macroeconomic time series in the US is Kydland and Prescott (1990). Their major findings, many of them having proved to be robust to alternative sampling periods and cyclical filters provided the empirical impetus for much of early Real Business Cycle (RBC) research. Among other results, Kydland and Prescott find that aggregate variables are in general highly persistent, output being more volatile than consumption, but less volatile than investment. Most variables appear to be procyclical including money, employment, investment, consumption, imports, exports and productivity. Important acyclical variables are the price level, net exports and the real wage.

Countercyclical variables are few; they primarily include government consumption and the capital stock.

In the international context, Fiorito and Kollintzas (1994) are one of the pioneers in establishing quarterly frequency facts in countries other than the United States. Using the H-P filter, they isolate the cyclical components of quarterly frequency observations of major macroeconomic variables over the period of 1960 to 1989 in the G7 countries, Canada, Germany, France, Italy, Japan, the UK and the US. ${ }^{3}$ Conforming to most of the findings in

\footnotetext{
${ }^{2}$ Countries in the CEE region broadly defined excluded from this study for the paucity of appropriate data are Albania, Armenia, Azerbaijan, Belarus, Bosnia and Herzegovina, FYR Macedonia, Georgia, Kazakhstan, Kyrgyzstan, Moldova, Serbia and Montenegro, Tajikistan, Turkmenistan, Ukraine and Uzbekistan.

${ }^{3}$ An important predecessor to Fiorito and Kollintzas (1994) is Danthine and Donaldson (1993). Ahmed et al (1993), Backus and Kehoe (1992), Basu and Taylor (1999) and Bergman
} 
Kydland and Prescott (1990), they show that consumption is procyclical and tend to fluctuate less than output, investment is procyclical, fluctuating more than output, net exports are countercyclical, prices are countercyclical, and government consumption and money have no unambiguous pattern. In a related work, employing a number of alternative de-trending procedures including the H-P filter, first-differencing and fitting a quadratic time-trend polynomial, Christodoulakis et al (1993) study business cycle fluctuations in twelve EC countries. Robustly to the specifics of de-trending, they again find that output, consumption, investments, prices and net exports behave fairly similarly across countries, while monetary aggregates, government spending and terms of trade evolve with no clear pattern.

Artis and Zhang (1997) investigate the degree of business cycle conformity in countries comprising of the ERM in 1993, and some other OECD countries such as Japan, Canada, the UK, Sweden, Finland and Norway. The reference countries are the US and Germany. Using monthly data for the period of 1961:1 to 1993:12, their main focus is on documenting the contemporaneous, and lead and lag cross-correlations in a single macroeconomic variable, de-trended industrial production. Robustly to de-trending by different filters, Artis and Zhang find that before the formation of the ERM, business cycles in their sample were typically linked to the US cycle. After the ERM came into existence in April 1979, fluctuations in industrial production in ERM countries began to move together with the corresponding cycle in Germany, the same shift not having occurred in Canada or in the other non-ERM countries. ${ }^{4}$

While the vast majority of related research focuses on developed economies, there is also a growing literature analyzing developing countries, though often in a narrow way. These papers are either limited to pairwise correlations among a small group of countries, such as Alper (2003), Mendoza (1995), Kouparitsas (1997), and Kose and Reizman (1998); or a single country, such as Bjornland (2000), Burgoeing and Soto (2000), Kydland and Zaragaza (1997), and Rodriguez-Mata (1997). Alper (2003) for instance examines the quarterly frequency cyclical properties of the Mexican and Turkish economy over the period of 1987 to 2000 . Among other things, he finds that the volatility of output is significantly higher in both countries than in the United States, and that consumption expenditures are even more volatile than output. Government consumption is procyclical but is not leading the cycle. Employment and productivity are procyclical. The comovement between real activity

et al (1998) focus on long-span samples of annual frequency aggregate data in a few industrial countries.

${ }^{4}$ Artis and Zhang (1999) follow up on their previous work by extending the sample period to 1995:10 and the number of countries examined to 19. In addition to confirming most prior findings, they also document that the degree of business cycle synchronization and exchange rate variability are negatively correlated across countries. Agresti and Mojon (2001) also study regularities in Euro-area business cycle. 
and different measures of the money supplies show no clear-cut pattern. The price level and inflation are countercyclical. ${ }^{5}$ Gross capital inflows are procyclical and lead the cycle.

Agénor et al (2000) is a large step in unifying the two branches of the literature.

Using quarterly data over the period of 1978:1 through 1995:4, they document a wide set of findings of cyclical variability and covariance for 12 developing countries: Chile, Colombia, India, the Republic of Korea, Malaysia, Mexico, Morocco, Nigeria, the Philippines, Tunisia, Turkey and Uruguay. The variables analyzed include industrial output, the price level and inflation, nominal and real wages, monetary aggregates and their velocity, domestic private sector credit, fiscal variables such as gross and net government expenditures and revenues, nominal and real exchange rates, and the trade balance. For robustness, in obtaining the cyclical component of time series, after first being deseasonalized, all of these variables are de-trended by two alternative filters, the Hodrick-Prescott filter and the Baxter-King bandpass filter. Agénor et al find that cyclical output, as proxied by industrial production is persistent, and much more volatile in developing countries than in industrial ones.

Government expenditures are countercyclical. There is no clear pattern in the cyclical behavior of nominal wages and prices, nominal and real exchange rates, but real wages are strongly procyclical. The correlation between monetary aggregates and output is in general positive, but not very strongly so. The velocity of broad money tends to be strongly countercyclical. The contemporaneous correlation between output and the terms of trade is positive.

Overall, while evidence on business cycle frequency economic fluctuations is becoming available from an increasing number of countries and time periods, no study to our knowledge has aimed at systematically documenting business cycle facts in a major segment of emerging markets, transition economies. In the current project, we seek to pursue this task.

We managed to assemble a relatively comprehensive data set of macroeconomic variables in CEE economies. Our primary data sources are the International Financial Statistics, local central banks and statistical offices, the Emerging Market Database, the Economics Intelligence Unit, and the WIIW monthly database on Eastern Europe. ${ }^{6}$ Multiple sources allow for crosschecking the reliability of data in many instances, we thus believe that the quality of our sample is the best one can possibly to hope for in this context. As some of the

\footnotetext{
${ }^{5}$ Chadha and Prasad (1994) find that inflation is procyclical in the G-7 economies, though the price level is countercyclical.
} 
transition countries did not exist before 1993, or the coverage and quality of data is simply problematic before this time, our common sample ideally consists of 40 quarterly observations from 1993:01 to 2002:04. For countries like Hungary or Poland, a number of the relevant variables exist at the quarterly frequency even before 1990. At the same time, in these same countries GDP and its components were not collected until 1995. To ensure comparability in terms of the time period, external shocks and data quality, we used only the restricted sample in these cases. ${ }^{7}$

We focus on the following aggregate variables: real GDP, industrial production, private consumption, gross fixed investment, government consumption, exports, imports, net exports, industrial employment, industrial productivity, real wages, private sector credit, M1, M2, velocity of M1, velocity of M2, CPI, inflation, nominal effective exchange rate, real effective exchange rate. ${ }^{8}$ These variables include most of the standard choices of the corresponding literature. Private sector credit, inflation and measures of the exchange are added to ensure meaningful comparisons with the developing country data analyzed in Agénor et al (2000). Fiorito and Kollintzas (1994) also analyze the properties of real interest rates, defined as the difference between nominal rates and realized future inflation. Such a procedure would be questionable in our sample, due to typically high and volatile inflation, thus we omit the study of real interest rates. Certain variables like hours worked, terms of trade, FDI or portfolio investment flows, more detailed productivity data tend to be inaccessible at the quarterly frequency.

The listed variables are however available for most countries over the entire time period. Unfortunately, none of the countries have a perfect record, GDP and its components being the most notorious missing variables. Occasionally, some of the endpoints are missing, which means that certain variances and correlations are obtained from 39 observations. In Hungary and Poland the figures for GDP and its components are available only from 1995:1 onwards, in the Czech Republic from 1994:1 onwards. Although available from 1993:1, in order to avoid using irregularly behaving price data from the early transition years of 19931994, the sample in Croatia is restricted to the period of 1995:1 - 2002:4. For Bulgaria, one of the main bottlenecks is industrial production, which is available monthly, but only in 12month changes (i.e., it is not the change relative to the previous month, but the corresponding month of the previous year). Without monthly increments in the first year, one cannot invert this data into quarterly indices. Using this variable, on the other hand, could substantially

\footnotetext{
${ }^{6}$ Table AI summarizes information on data sources and coverage.

${ }^{7}$ We do robustness checks with extended time periods, and even try to look at "socialist business cycles". Of course, one needs to be particularly careful with interpreting this latter type of results.

${ }^{8}$ The Appendix contains further details of the definition of the variables used.
} 
alter results since 12-month changes have very different cyclical properties than actual quarterly changes. ${ }^{9}$

Prior to the analysis, the raw data need to be transformed. First, all variables are deseasonalized using the X11 procedure of Eviews, with multiplicative adjustment (the only exception being inflation, where the adjustment was additive). We have not explored whether the results would remain similar with alternative procedures (like the Tramo-Seats method). The reason for selecting the X11 procedure was to ensure comparability with the literature. For the same reason, we have used the adjusted series even if seasonality was rejected -- in such cases, the adjusted series remained almost identical to the original anyway. For ratios (and other generated variables), we divided the adjusted series with each other, and worked with these variables (did not adjust the ratio).

Next, we need to control for stationarity and seasonality in the series. Some of the macro variables have a trend even in developed economies but such a behavior is much more prevalent in emerging ones. As documented in Canova (1998), and then confirmed in Agénor et al (2000), cyclical patterns may depend on the particular de-trending procedure adopted. In this spirit, we have decided to use several approaches, and report the basic statistics for most of them. Our current choices are the H-P filter with parameter 1600 (the standard choice for quarterly data), log first differences (might look problematic with trending variables, but the results turned out to be quite similar with this choice as well), and fitting a quadratic time polynomial. These coincide with the choice of Fiorito and Kollintzas (1994), and Christodoulakis et al (1993). ${ }^{10}$ In almost all cases, filtering was applied to the natural logarithm of the series. One of the exceptions is inflation, which is already in log-difference form, so the series itself could be filtered. Another exception is net exports, which can be both negative and positive. For this reason, similarly to Kydland and Zarazaga (1997), Agénor et al (2000), we employed the ratio of net exports to output in percentage terms. ${ }^{11}$

Notice that in this case, the use of a pure manufacturing index is problematic for volatilities (though not for correlations); the scale is invariant within a country, but not across countries. In all other cases, taking logs and then de-trending takes care of country-specific

9 ...We expect to be able to get the quarterly version of this variable. Romanian GDP data is currently available only from 1997:1. We are in the process of obtaining earlier data via direct contact to the Central Bank.

${ }^{10}$ Agénor et al (2000) use the band-pass filter of Baxter and King. We refrain from the bandpass procedure, since our near-forty quarterly observations may constitute too short of a period.

${ }^{11}$ Instead of removing the trend component and then looking at variances, covariances, leads and lags, an alternative approach to follow is the turning point methodology of Harding and Pagan (2002). The idea here is to define turning point events in a statistically precise manner and relate them to actual changes in the series of interest, as opposed to the evolution of deviation from some trend. Exploring the data using this approach is the subject of ongoing research. 
scaling. With net exports to GDP, we have scaled its volatility by the ratio of the nominal production index (output index times CPI) and true nominal GDP. Also, to conform to the employment data representing total hours in the manufacturing sector, productivity is computed using industrial production data.

4

\section{RESULTS}

Before looking at the variances and covariances in more detail, it is useful to have a bird-eye view of the output data to see if they show any cyclical pattern. Figures 1 to 3 show the evolution of GDP and industrial output in Estonia, Poland and Slovenia. The graphs confirm that GDP, and especially industrial output indeed follow a strong upward trend with notable ups and downs. We can clearly see an initial transition bust, followed by a robust expansion, broken by the apparent effect of the Russian crisis. In some quarters, growth has picked up, with an unclear cyclical behavior through the global slowdown recession starting around 2000. Overall, this is the standard picture one could expect, showing some visible, though not absolutely clear cyclical pattern.

It is also instructive to look at summary statistics of output fluctuations in CEE countries and compare them to ones documented in other regions. Table I reports measures of volatility and autocorrelation in H-P-filtered output. Overall, output is more volatile in transition countries than in developed economies, and is about as volatile as in other developing ones. Some of this phenomenon might be related to differences in sample size; most other results in the literature are obtained from 15-30 years of quarterly data, where the trend component can be extracted more precisely, and the endpoints are less influential. For GDP, average output volatility in transition countries is about the same as in the small number of developing countries we have data for, and somewhat higher than in the EU countries.

The persistence in output is similar across all countries in the table; the first two autocorrelations are typically significant, and the third one is marginally significant. Persistence is particularly high in G7 economies as compared to any other group of countries. This is also true for the transition sample, especially after dropping the major outlier, Lithuania. In addition, the degree of persistence appears to be related to country size with the clear exceptions of the Czech Republic in the transition group and Belgium in the EU one. All in all, one of the major conclusions is that fluctuations in transition economy output are not drastically different from fluctuations in developed or other developing countries.

A number of related studies report facts of economic fluctuations by proxying output only with industrial production. In contrast, we use real GDP as a measure of output. In order 
to provide a basis of comparison for our findings to this literature, we first examine properties of industrial production data in transition economies. Table II displays the degree of volatility, cyclicality and persistence in industrial production in CEE countries. ${ }^{12}$ The data indicate that industrial production is highly volatile, about as volatile as in other developing countries analyzed in Agénor et al (2000). Relative volatility is relatively stable across countries, indicating some uniformity in the industrial sector shaping fluctuations in GDP. Industrial output is also strongly procyclical, synchronous and persistent. The major exceptions in cyclicality are Bulgaria and Slovenia with the lowest correlation coefficients of 0.35 and 0.38 , respectively.

Tables III through XX summarize the results for the three major groups of variables, output components (consumption, investment, government consumption, net exports, real imports, real exports), production input related variables (industrial employment, real wages, productivity) and monetary variables (private sector credit, M1, M2, M1 velocity, M2 velocity, CPI level, CPI inflation, nominal and real effective exchange rates). For these variables, the following statistics are reported: absolute volatility (standard deviation), volatility relative to output, contemporaneous correlation with output, measures of the phase shift (correlations between the variable itself, and lagged and leaded output) and persistence (first-order autocorrelation coefficient). While we compute and report many of our result with all three alternative filtering procedures (H-P, first difference and time polynomial), and most results prove to be robust to filtering technique, our interpretation of findings is always based on H-P filtered data. Since the number of observations is around 40, the associated $95 \%$ significance level of correlation coefficients is about 0.3 .

\section{Components of output}

Consumption. The absolute and relative volatility of consumption is higher in all transition countries where the data available than in the US. Many of the countries have even higher consumption volatility than other developing countries, such as Argentina, Mexico and Turkey. The comparison is even more striking with the EU and G7 countries. For instance, the UK has the largest relative volatility of 1.19 in G7, which is almost the same as for Poland, being the smallest one in our sample with 1.06. One might conclude that excessively high volatility contradicts the theoretical prior of consumption smoothing. The standard candidate for explaining this puzzle is the exclusion of durable consumption from the data; such a correction for instance resolves the issue for the UK (Backus, Kehoe and Kydland (1995)). For transition economies with rapid income growth and changing consumer behavior, durables are also likely to be both important and volatile.

${ }^{12}$ We also have results of the comovement of industrial production with all the other relevant 
Private consumption is highly procyclical. The contemporaneous correlation between consumption and GDP is positive, often significantly so. The magnitude of the coefficients appears to be similar to ones found in industrial countries. There is no systematic pattern for lagged correlations, but that is also true for EU countries. Moreover, whether output is proxied by real GDP or industrial output does not seem to alter the cyclical properties of consumption. The persistence in consumption is relatively high, though lower than in the US. The two notable outliers are Latvia and Lithuania.

Investment. Investment is highly procyclical and is in general coincidental. The volatility of investment is very high in international comparison, especially relative to industrial countries, both in relative and absolute terms. Indeed, it is most volatile component of aggregate spending in all countries. High volatility by international standards might stem from data issues, like measurement problems (classification of certain items); or the privatization of a large portion of previously government owned physical assets. Investment also tends to be persistent, with the exception of Latvia, and to some extent, Hungary and Romania. It is least persistent in Romania and in countries with the most stable exchange rate regimes, Bulgaria, Estonia, Hungary, Latvia and Lithuania. Indeed, Latvia happens to be the country with the highest absolute volatility, lowest persistence and correlation in investment among CEE economies. Poland and Russia exhibit the strongest correlation between investment and output. Interestingly, Poland and Russia also happen to be the countries with the largest in size, and the tightest restrictions in international capital flows and trade.

Government consumption. Governments play a large and central role in all transition economies, and their prudence is one of the key criteria of EU and EMU accession. For this reason, budget items are often moved across years or budget categories, creating extra artificial volatility of spending, transforming its dynamics in an uncertain way. Given this caveat, government consumption is more volatile than in industrial countries, and about as volatile than in developing countries. In addition, government spending tends to be more volatile than private consumption, and less volatile than investment in the sample. If anything, government consumption tends to be procyclical, with Latvia and Poland being countercyclical, and Estonia and Hungary acyclical.

Net exports. With the exception of Russia with a procyclical trade balance, all signs of the cyclicality statistics are in line with the experience of countercyclicality in developing and G7 countries. ${ }^{13}$ Russia is also the country with the highest degree of persistence. While net export tends to be the least volatile component of GDP, less volatile than private

aggregate variables in these countries. These results are available upon request.

${ }^{13}$ Net exports are expected to be procyclical in a country relying on large scale commodity exporting as the primary source of national income. 
consumption, the magnitude of relative volatility is dramatically higher than the corresponding statistic in the US, the latter being 0.45 (see Kydland and Prescott (1990)).

Imports. The volatility of imports relative to GDP tends to be larger than the one for industrial countries, the largest being France with a ratio of 4.57. In our sample, Hungary and Slovakia are notable outliers in relative terms. In absolute terms, Bulgaria, Estonia, Lithuania and Romania show particularly strong volatilities. The sizeable relative volatilities in Hungary and Slovakia might be related to heavy re-exporting activities in these countries. Large and relatively closed countries seem to show relatively little cyclical volatility in importing. Russia for instance has the smallest relative volatility in the sample. Just like in G7 countries, imports are always strongly procyclical and approximately coincidental in all countries. Slovakia is an exception here, with no significant correlation coefficient.

Exports. Again, relative export volatilities in CEE countries exceed those in industrial countries. Exports are strongly procyclical in Russia, a major oil exporter country, and also in countries with the most open goods and capital markets, such as Estonia, Hungary, Latvia and Lithuania. There is scattered evidence for phase shifts. None of the observed patterns are inconsistent with G7 results. For example, the US also has a strong negative leading correlation, Canada has a medium-high positive lead, and Italy has a medium-high negative lagged correlation.

\section{Production inputs}

Employment. Employment in CEE countries tends to be more variable than in industrial ones, Bulgaria showing a very high degree of absolute volatility. Indeed, employment variability exceeding GDP variability appears to be the rule rather than the exception. Cyclical patterns in employment are very similar to G7 results; with the exception of Slovenia, employment is clearly procyclical, often synchronous in a statistically significant way. Unlike to G7 economies where employment lags output, the phase shift pattern here is more mixed, with leading or coincidental coefficients being slightly more prevalent than lagging ones. In this sense, the phase shift of employment is more favorable to RBC theories of the business cycle not positing labor hoarding. With exception of Russia, cyclical employment is quite persistent.

Real wages. The relative volatility of real wages is again significantly higher here than in G7 economies, particularly so in Russia. Apart from potential measurement issues, high volatility might be attributed to the interaction of cyclical fluctuations and the trend real convergence process in these countries. In contrast to the evidence in industrial countries, significant positive correlation coefficients dominate negative and zero ones, though the phase shifts show no unequivocal pattern. Economic theory suggests that procyclical wages are consistent with technological shocks, while preference or government expenditure shocks 
can lead to countercyclical wages. Cross-country differences in wages may thus indicate the relative importance of these shocks. It also seems to be the case that countries with more persistent real wage tend to exhibit higher output volatilities.

Productivity. Similarly to developed economies, this variable shows strong positive correlation with output, often without a phase shift. In some cases, the positive contemporaneous correlation is accompanied by high, statistically significant negative lead correlations, as in Russia and Slovenia, or negative lagged correlation as in Bulgaria and Slovakia. Absolute and relative volatilities in cyclical productivity are in general fairly high in many countries, well exceeding similar statistics in developed economies. The data also point to some persistence in productivity fluctuations.

\section{Monetary and other nominal variables}

Private sector credit. Unlike Agénor et al (2000), we find some pronounced pattern in these countries. The relative volatilities in many countries appear to be fairly high, though there is no international comparison available in this respect. Absolute volatility in Bulgaria is truly astronomic, potentially explained by the hyperinflation experience in 1997. Private sector credit is procyclical with the exception of Lithuania, and is uniformly highly persistent. As pointed out by Agénor et al, a strong positive sign can have important consequences for the cost of restrictive monetary policy if credit leads the cycle. In the current sample however credit is dominantly lagging the cycle, or concurrent with it.

M1. Relative volatilities in M1 in our sample are similar to, or larger than the ones in the US or G7 economies. Volatility is again particularly high in Bulgaria, and to a lesser extent in the Czech Republic, Slovakia and Slovenia. Given the high or moderate inflation history in most CEE countries, large volatility should come at no surprise. M1 is least volatile in countries adopting fixed exchange rates early in transition, Estonia, Hungary, Latvia and Lithuania. M1 is in general highly persistent, procyclical, and rather leading or coincidental. Slovenia again shows a somewhat strange pattern with correlations being insignificant at all leads and lags. Bulgaria, Estonia and Lithuania are exceptions in terms of cyclicality with a significant negative correlation between M1 and output. The largest correlation coefficient in absolute value in Hungary is negative and leading, but Hungary also shows large, negative lagging coefficients. While Kydland and Zarazaga (1997) also find M1 to be countercyclical using their "new version" of GDP estimates in Argentina, money moving the opposite direction to output is unprecedented in industrial countries.

M2. Apart from Hungary and Slovakia, absolute volatilities are large, larger than for the G7 group, but never as high as in Argentina. Overall, M2 behaves similarly to M1; it tends to be procyclical or acyclical, like in the G7. M2 in Bulgaria, Hungary and Lithuania, 
and to a lesser extent in Estonia shows significantly countercyclical behavior, a pattern being similar to the one in Argentina.

M1 velocity. M1 velocity tends to be procyclical and leading the cycle. Its relative volatility varies across countries, but its range is not too different from that of G7 countries. Unlike in G7 countries with velocities being more volatile than M1, velocity fluctuates about as much as money itself in all countries in our sample.

M2 velocity. M2 velocity fluctuates less than M2. M2 velocity also tends to be procyclical, but shows no clear pattern in leading or lagging the cycle.

$C P I$. Since a large and changing fraction of prices is in the regulated category in CEE economies, one would not expect a very clear and interpretable cyclical pattern of the CPI. Surprisingly, most of the countries still exhibit countercyclical, and weakly leading or coincidental behavior of the price level. This behavior is similar to that of the G7, and it is usually interpreted as supporting the RBC approach with a shifting aggregate supply and a stable aggregate demand. Prices are procyclical only in Russia and acyclical in Poland. With Croatia and the Czech Republic being exceptions, the CPI shows a much larger absolute volatility than in industrial countries. Reflecting the large nominal shock associated with the hyperinflation period in 1997 and the crises in 1998, prices are particularly volatile in Bulgaria and Russia, respectively. Presumably associated with the high trend inflation and the inflation surge episode in 1997, Romania also exhibits highly volatile prices, both in absolute and relative terms. The Baltic countries appear the form another group with moderately high absolute volatility figures. The CPI is in general highly persistent in most countries. Croatia has the least persistent and least volatile CPI.

Inflation. As argued by Chadha and Prasad (1994), finding indeed significantly positive correlation between inflation and output in G7 countries, it is the behavior of inflation and output that should determine the relative importance of demand- versus supplydriven shocks. Though the relevant negative correlation coefficients outnumber the positive correlation coefficients, the highly mixed lead and lad patterns make inflation in CEE economies show no unambiguous cyclical pattern. Inflation is not particularly volatile in most countries, the exceptions being Bulgaria, Lithuania, Romania and Russia. Estonia, Romania and Russia stand out by having inflation that is not only persistent but also negatively correlated with GDP. ${ }^{14}$ Persistence in inflation tends to be low in the other countries.

Nominal effective exchange rates. The data in Bulgaria and Russia show unusually high absolute and relative volatilities. Absolute volatilities are also high in Estonia, Lithuania and Romania. These observations are partly explained simply by the large discrete jumps, 
associated with changes in the exchange regime passed through the filters, partly by high the high inflation episodes, especially in Bulgaria, Romania and Russia. Still, even the highest relative volatilities are smaller than the one documented in Argentina. On the other hand, the data in Croatia and the Czech Republic show notably small relative volatilities. Country size and openness do not seem to have a bearing on the degree of volatility. In general countries with less volatile nominal effective exchange rate also appear to have less volatile price levels. While all series are highly persistent, cyclical correlations tend to exhibit procyclical behavior, with Estonia, Lithuania and Poland being countercyclical and Slovenia acyclical. Phase shifts show a mixed pattern.

Real effective exchange rates. Absolute and relative volatility figures are in general on the same order of magnitude as the ones for nominal rates. Real exchange rates in Bulgaria, Romania and Russia are again particularly volatile in absolute term, but show muted volatility in Croatia, the Czech Republic and Estonia. Relative volatility in real exchange rate is exceptionally high only in Russia. Real exchange rates appear to be mostly countercyclical, with the exception of Bulgaria, Croatia, the Czech Republic and Russia being countercyclical, and Slovenia acyclical. Comparing cyclicality in real with nominal exchange rates, we find significant sign switches for Hungary, Romania and Slovakia; otherwise signs, and often phase shifts remain intact. Countries in which volatility in real effective exchange rates exceeds or very close to the corresponding nominal figure include the Czech Republic, Croatia, Poland and Slovenia. Phase shifts again show no systematic behavior.

\section{CONCLUSIONS AND NEXT STEPS}

The central tendency in CEE economic fluctuations shows several interesting patterns. First, industrial production is highly volatile, strongly procyclical, synchronous and persistent. Consumption is excessively volatile, typically procyclical, and persistent. Investment also tends to be volatile, procyclical, and in general coincidental. Countries with more fixed exchange rate regime exhibit less persistent investment. Investment is more procyclical in large and more closed economies. Government consumption shows no definite cyclical pattern, though it more volatile than in other groups of countries. Net exports are countercyclical and again highly volatile. Overall, investment is the most volatile component of GDP, followed by government consumption, private consumption and net exports. Large and relatively closed countries show little cyclical volatility in importing. Exports are highly

\footnotetext{
${ }^{14}$ The cyclical properties of the unfiltered inflation series show virtually identical patterns.
} 
volatile, and procyclical in countries with open goods and capital markets. Phase shifts so no clear pattern.

Employment is excessively volatile, procyclical, often synchronous, and does not lag output. Real wages are also volatile, typically procyclical. Countries with highly persistent real wage tend to exhibit high output volatilities. Productivity is procyclical and shows no phase shift. Volatility in productivity in CEE economies well exceeds the one in developed economies. Persistence in productivity is fairly moderate. The behavior of the standard production input variables (employment, real wages and productivity) is in many respects similar to related patterns documented in industrial countries, emphasizing the role of real shocks. It is also consistent with a strong technological improvement interpretation of the mature transition process. In fact, employment behaves closer to RBC theory in transition economies than in industrial countries.

Private sector credit is highly volatile, persistent, procyclical in most countries, and tends to lag the cycle. The money stock is in general volatile, highly persistent, procyclical, and rather leading or coincidental. Velocity tends to be procyclical. M1 velocity leads the cycle in almost all countries, while M2 velocity is approximately coincidental. The price level is countercyclical, and weakly leading or coincidental with GDP, supporting the importance of shocks of the aggregate supply type. The CPI is highly persistent in most countries. Inflation is not particularly persistent and volatile, and tends to show countercyclical patterns. Countries with less volatile nominal effective exchange rate also appear to have less volatile price levels. While all nominal exchange rate series are highly persistent, cyclical correlations exhibit no common pattern. Real exchange rates appear to be mostly countercyclical. Volatilities in nominal and real effective exchange rates are in general on the same order of magnitude. Phase shifts in real exchange rates show no systematic pattern.

Countries in the sample can potentially be clustered further along many different dimensions. Indeed, pronounced cross-country differences in business cycle facts can be related to time-invariant country characteristics. For instance, countries with more fixed exchange rate regime exhibit less persistent investment, more volatile imports, exports, money stock and prices. Investment is more procyclical in large and more closed economies.

Overall, most of the countries show surprisingly similar cyclical behavior to the US and other industrial countries. As expected, the majority of economic variables are more volatile both in absolute terms and relative to output. Transition economies appear to be more similar to industrial countries than the developing countries considered by Agénor et al (2000), or other country studies. Of course, there are important exceptions, which require further analysis. 
In addition to the more detailed international comparison offered in Benczúr and Rátfai (2004), there are a number of directions to which the current analysis is extended. First, as new, and new releases of old, data become available, we seek to update our sample, and our results with data points. We also plan to add new countries and variables to this enterprise as the relevant data constitute a meaningful object of investigation. Second, we plan to investigate the robustness of our qualitative results to alternative de-trending procedures, such as the band-bass filter of Baxter and King. Third, we are about to examine economic fluctuations in CEE countries using the 'turning point' approach of Harding and Pagan (2002). Fourth, we continue on seeking to cluster countries further according to their cyclical patterns, and connect the results to country characteristics, such as size of the shadow economy, exchange rate regime, financial integration, fiscal and monetary policies etc. Fifth, in some of the countries quarterly data goes back to the mid- or late-1980s. For certain countries, even longer time series of data can be available at the annual frequency. What does such historical data show? While it is clear that one has to be very cautious and modest when looking at old data from the former Soviet block, some pattern may still show up. Finally, in a more structural empirical framework, we are investigating the contribution of Euro-zone shocks to economic fluctuations in CEE countries, the role of different transmission channels, and the evolution of these patterns through time. We expect to find that determinants of aggregate dynamics are tied to increased integration in trade and financial markets. 


\section{APPENDIX}

Real GDP. For Croatia, Hungary, Latvia, Lithuania, Poland and Slovenia, real GDP is the 1995-prices GDP volume index (IFS series 99bvp), for the Czech Republic and Slovakia, it is the 1995-prices GDP (series 99b.p). For Bulgaria and Estonia, it is a fixed price GDP from the Statistical Office. For Romania, it is a fixed price GDP from the Institute of Economic Forecasting. For Russia, 1995- and 2000-prices GDP series of the Emerging Markets Economic Database are chained together: starting from 2000-prices GDP at the end, annual changes of the 1995-prices GDP are traced back before 2000.

Industrial production. For Croatia, the Czech Republic, Hungary, Lithuania, Romania, Slovakia and Slovenia, industrial production is a volume index (IFS series 66). For Estonia, the quarterly series are obtained from the monthly index of industrial sales (provided by the Central Bank), each quarter being the 3-month average. For Latvia, the change in the constant-price industrial production index of the Statistical Office is cumulated. For Poland, the WIIW series of monthly changes in industrial production is cumulated, and the last month is taken as the quarterly observation. For Bulgaria, the WIIW series of annual changes in the quarterly average of industrial production is matched with the corresponding level series of the Statistical Office. For Russia, the Economic Intelligence Unit's four industrial production series (91 prices, 95 prices, 97 prices, changes in the index with 1999 prices) are merged into a common series of quarterly changes, which is then cumulated. Each sub-series is used till its last observation, and then the change in the next variant continues.

Private consumption. Private consumption includes Non-Profit Institutions Serving Households (NPISH). For the Czech Republic, Hungary, Latvia, Lithuania, Poland, Romania, Russia and Slovakia, private consumption is household consumption expenditures in current prices (IFS 96f). For Bulgaria, Estonia and Romania, it is private consumption expenditures in current prices obtained from the Statistical Office.

Investment. Investment is gross fixed capital formation, in current prices. It is obtained from the Statistical Office for Bulgaria, Estonia and Romania, and IFS series 93e for all other countries. Investment data in Croatia and Slovenia are unavailable.

Government consumption. Government consumption is government consumption expenditures in current prices. It is obtained from the Statistical Office for Bulgaria, Estonia and Romania, and IFS series 93e for all other countries. Government consumption data in Croatia and Slovenia are unavailable.

Exports. For Bulgaria, the Czech Republic, Estonia, Hungary, Latvia, Lithuania, Poland and Slovakia, exports are merchandise exports in local currency (IFS series 70). For Croatia, Romania, Russia and Slovenia, we use the monthly figures in dollars (70d for Croatia, 
Romania and Russia, Central Bank data for Slovenia). These are converted into local currency using monthly average exchange rates (IFS series $r f$ for Croatia and Romania, WIIW series for Russia, Central Bank series for Slovenia). Quarterly observations then correspond to the 3-month sum of exports.

Imports. For Bulgaria, the Czech Republic, Estonia, Hungary, Latvia, Lithuania, Poland and Slovakia, imports are merchandise imports in local currency (IFS series 71). For Croatia, Romania, Russia and Slovenia, we use the monthly figures in dollars (IFS 71d for Croatia, Romania and Russia, Central Bank for Slovenia), and then follow the same procedure as with the exports series.

Wages. For Bulgaria, Croatia, the Czech Republic, Hungary, Latvia, Lithuania, Poland, Romania, Slovakia and Slovenia, wages are the series 65 of the IFS, while for Russia, it is the change in the same index (65x), cumulated. For Estonia, we use the Central Bank series on average quarterly wages, in national currency.

Employment and productivity. For Croatia, Hungary, Latvia, Lithuania, Poland, Russia and Slovenia, employment is the industrial employment index of the IFS (series 67). For Bulgaria, Romania and Slovakia, employment is industrial employment from WIIW: in thousands for Romania, while a monthly change for Bulgaria and Slovakia (cumulated). Quarterly observations for Bulgaria and Romania correspond to the last month of the quarter, while for Slovakia they correspond to the first month.

For the Czech Republic and Estonia, employment is total employment (in thousands), provided by the Statistical Office and Central Bank, respectively. In the Czech Republic, there exists quarterly frequency series of industrial employment; however, it excludes medium-size firms (with 20-100 employees) in the years of 1995 and 1996. For this reason, we do not employ this series. Correspondingly, productivity is defined as the ratio of real GDP to total employment for these two countries. For Lithuania, both the industrial production series and the total employment series are too short, so no productivity measure could be calculated.

Private sector credit. For Bulgaria, Croatia, the Czech Republic, Estonia, Hungary, Latvia, Lithuania, Poland, Russia, Slovakia and Slovenia, this variable is bank claims on other resident sectors (IFS series 22d). For Romania, the series of claims of non-government sector is obtained from the Central Bank.

M1. For Bulgaria, Croatia, the Czech Republic, Hungary, Latvia, Lithuania, Poland, Romania, Russia, Slovakia and Slovenia, M1 is the money series of the IFS (series 34). For Estonia, it is the series provided by the Central Bank in local currency.

M2. For Bulgaria, Croatia, the Czech Republic, Hungary, Latvia, Lithuania, Poland, Romania, Russia, Slovakia and Slovenia, M2 is the sum of the IFS series 34 (money) and 35 (quasi-money). For Estonia, it is provided directly by the Central Bank in local currency. 
Velocities of M1 and M2. They are defined as the ratio of the monetary variable and nominal output. Nominal output is obtained as the product of real GDP and the CPI.

CPI. For Bulgaria, Croatia, the Czech Republic, Hungary, Latvia, Poland, Romania, Slovakia and Slovenia, it is the price index series (64) of the IFS. For Russia, it is cumulated from changes (series 64x) in the IFS. For Estonia, it is the consumer price index provided by the Statistical Office. For Lithuania, we use the end-of-quarter observation of the monthly CPI-change series of the Central Bank.

Inflation. It is defined as the quarterly change in log of CPI. For the Czech Republic and Slovakia, the first observation is missing since there is no CPI data before 1993:1, the time for the breakup of Czechoslovakia.

Nominal and real effective exchange rates. For Bulgaria, Croatia, the Czech Republic, Hungary, Poland, Romania, Russia and Slovakia, effective exchange rates are trade weighted nominal and real exchange rate indices from the IFS (series nec and rec). For Estonia and Latvia, we use the quarterly real effective exchange rates series of the Central Bank, cumulated in Estonia. For Lithuania and Slovenia, we use the monthly nominal and real effective exchange rate series of the Central Bank, taking the last month in the quarter as the quarterly observation. Real exchange rates are CPI-based in all cases. 


\section{REFERENCES}

Agénor, Pierre-Richard, C. John McDermott and Eswar S. Prasad (2000):

"Macroeconomic Fluctuations in Developing Countries: Some Stylized Facts," The World Bank Economic Review, pp. 251-285

Agresti, Anna-Maria and Benoit Mojon (2001): "Some Stylized Facts on the Euro Area Business Cycle,” Working Paper \#95, European Central Bank

Ahmed, Shaghil, Barry W. Ickes, Ping Wang and Byung Sam Yoo (1993):

“International Business Cycles," The American Economic Review, Vol. 83, No. 3, pp. $335-359$

Alper, C. Emre (2003): "Stylized Facts of Business Cycles, Excess Volatility and Capital Flows: Evidence from Mexico and Turkey", Russian and East European Finance and Trade, forthcoming

Artis, Michael J. and Wenda Zhang (1997): "International Business Cycles and the ERM: Is There a European Business Cycle?" International Journal of Finance and Economics 2, pp. 1-16

Artis, Michael J. and Wenda Zhang (1999): "Further Evidence on the International Business Cycles and the ERM: Is There a European Business Cycle?," Oxford Economic Papers 51, pp. 120-132

Backus, David K. and Patrick J. Kehoe (1992): "International Evidence on the Historical Properties of Business Cycles," American Economic Review 82, pp. 864-888

Basu, Susanto and Alan M. Taylor (1999): "Business Cycles in International Historical Perspective," Journal of Economic Perspectives Vol. 13, pp. 45-68

Benczúr, Peter and Attila Rátfai (2004): "Macroeconomic Fluctuations around the Globe", manuscript

Bjornland, Hilde Christiane (2000): "Detrending Methods and Stylized Facts of Business Cycles in Norway - An International Comparison”, Empirical Economics, pp. 369-392

Bergman, U. Michael, Michael D. Bordo and Lars Jonung (1998): "Historical Evidence on Business Cycles. The International Experience", manuscript

Burgoeing, Raphael and Raimundo Soto (2000): “Testing Real Business Cycle Models in an Emerging Economy", manuscript

Canova, Fabio (1998): "Detrending and Business Cycle Facts," Journal of Monetary Economics, pp. 475-512 
Chadha, B. and Eswar S. Prasad (1994): “Are Prices Countercyclical? Evidence from the G7, " Journal of Monetary Economics, pp. 239-57

Christodoukalis, Nicos, Sophia P. Dimelis and Tryphon Kollintzas (1993): "Comparison of Business Cycles in Greece and the EC: Idiosyncracies and Regularities”, CEPR Discussion Paper \#809

Danthine, Jean Pierre and John B. Donaldson (1993): "Methodological and Empirical Issues in Real Business Cycle Theory,” European EconomicReview, pp. 1-35

Fiorito, Riccardo and Tryphone Kollintzas (1994): "Stylized Facts of Business Cycles in the G7 from a Real Business Cycle Perspective," European Economic Review, pp. 235-69

Harding, Don and Adrian Pagan (2002): "Dissecting the Cycle: A Methodological Investigation," Journal of Monetary Economics, pp. 233-251

Kose, M. Ayhan, and Raymond Riezman (1998): “Trade Shocks and Macroeconomic Fluctuations in Africa," Working Paper

Kouparitsas, Michael A. (1997): "North-South Terms of Trade: An Empirical Investigation," Working Paper 97-5, Federal Reserve Bank of Chicago

Kydland, Finn E. and Edward C. Prescott (1990): "Business Cycles: Real Facts and Monetary Myth," Federal Reserve Bank of Minneapolis Quarterly Review, pp. 3-18

Kydland, Finn E. and Carlos Zaragaza (1997): "Is the Business Cycle of Argentina Different?," Federal Reserve Bank of Dallas Economic Review, pp. 21-36

Lucas, Robert E. Jr. (1977): "Understanding Business Cycles”, Carnegie-Rochester Conference Series on Public Policy, pp. 7-29

Mendoza, Enrique (1995): "The Terms of Trade, the Real Exchange Rate and Economic Fluctuations," International Economic Review, pp. 101-137

Rodriguez-Mata, Margarita (1997): "Cyclical Patterns of the Costa Rican Economy," Working Paper, Central Bank of Costa Rica 

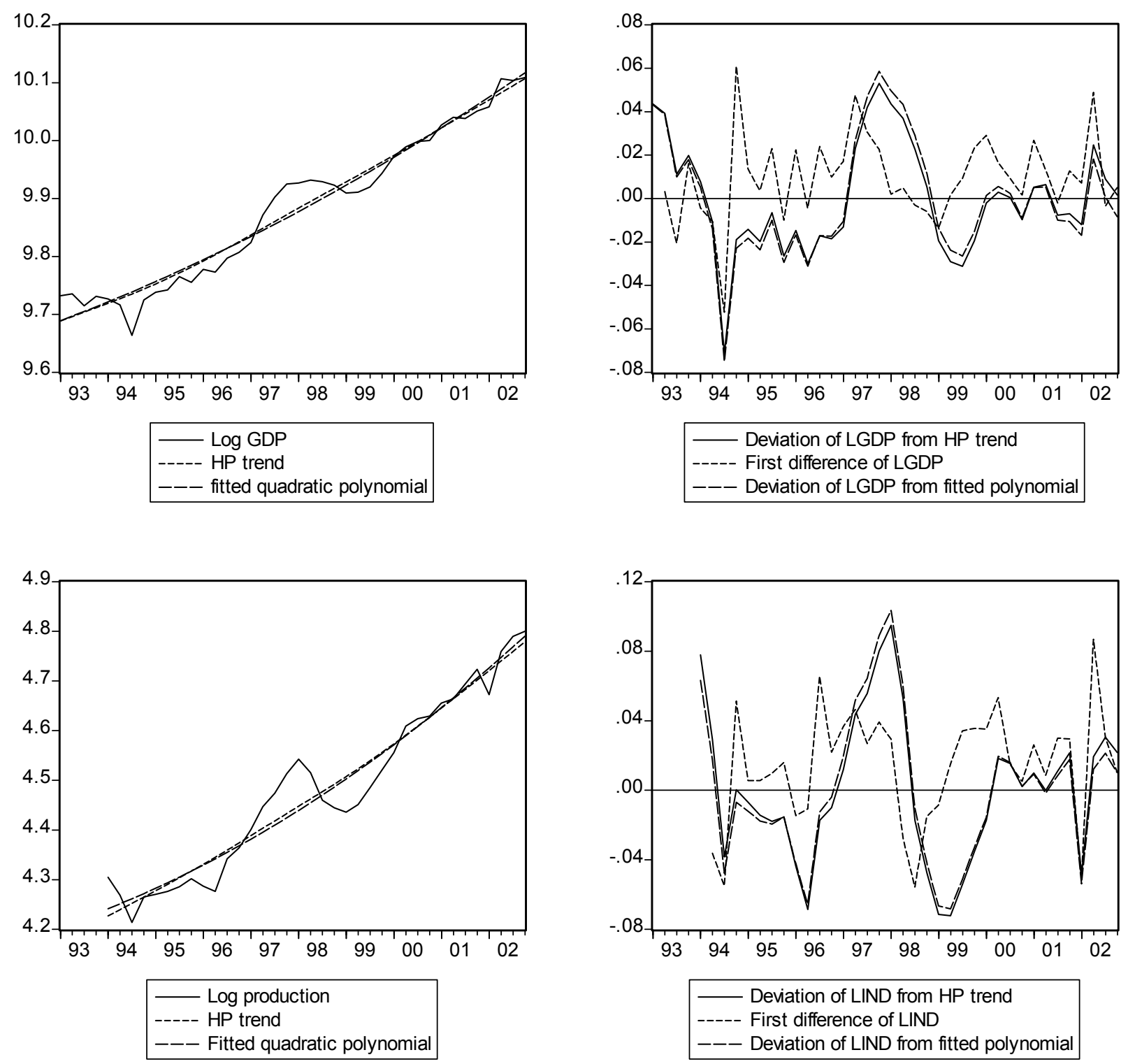

Figure 1: Estonia 

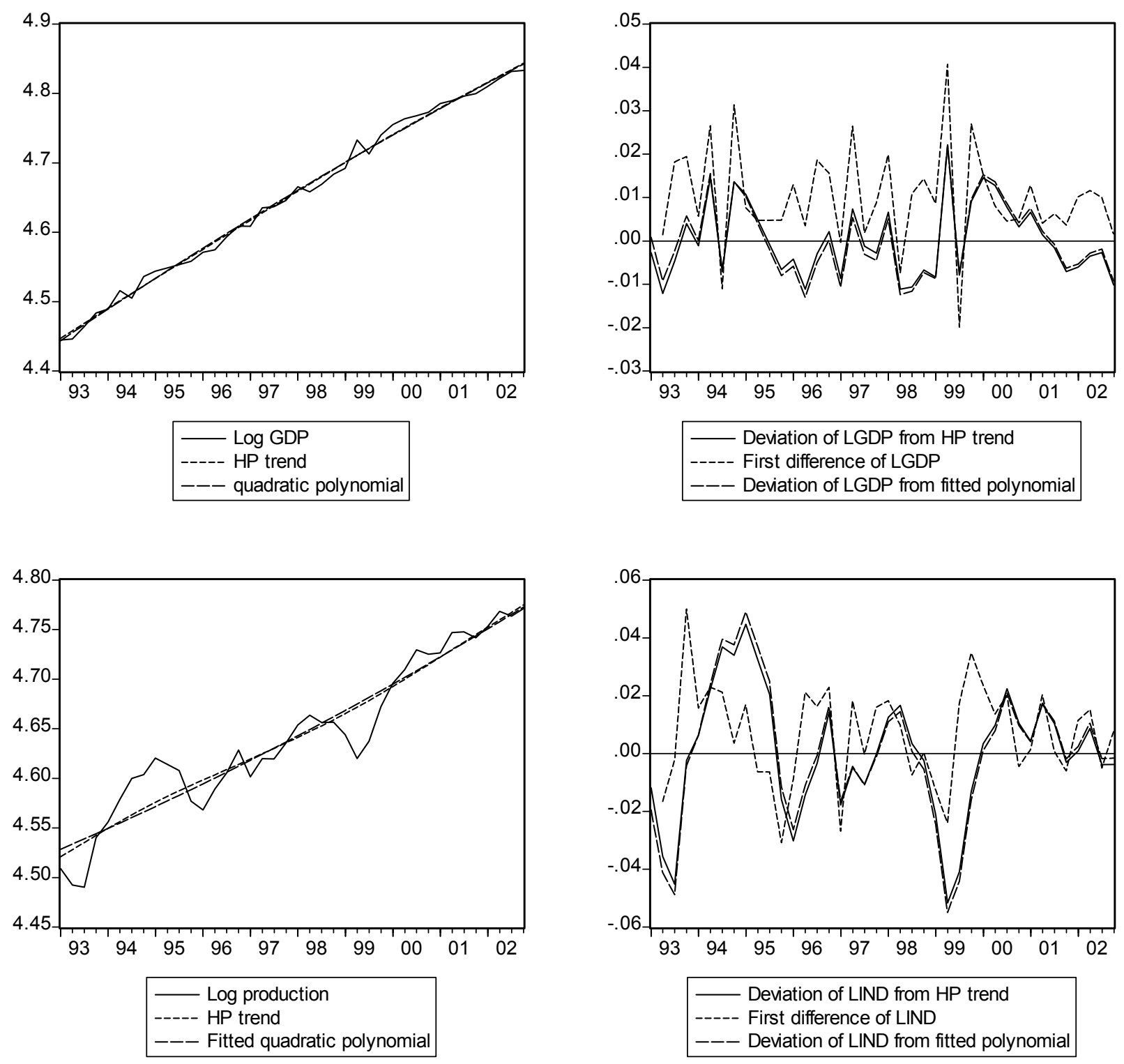

Figure 2: Slovenia 

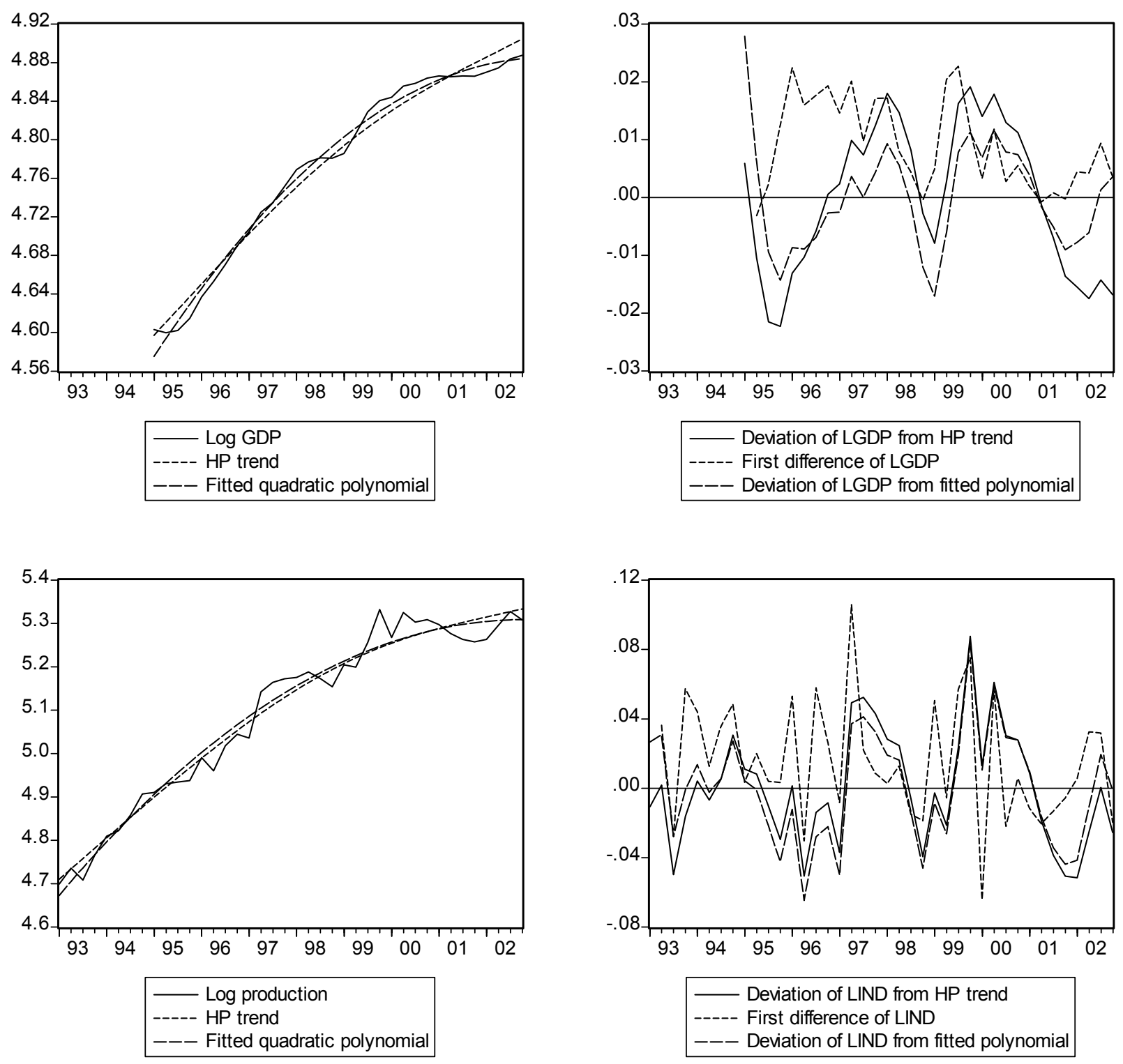

Figure 3: Poland 
TABLE I

SUMMARY STATISTICS FOR OUTPUT

\begin{tabular}{|c|c|c|c|c|c|c|}
\hline \multirow[t]{2}{*}{ Country } & \multirow[t]{2}{*}{ GDP Volatility } & \multirow[t]{2}{*}{ IP Volatility } & \multicolumn{4}{|c|}{ Autocorrelations } \\
\hline & & & lag1 & lag2 & lag3 & lag4 \\
\hline Argentina & $3.06 / 4.59$ & 5.57 & & & & \\
\hline Chile & 2.00 & 4.53 & 0.68 & 0.51 & 0.27 & 0.00 \\
\hline Colombia & & 2.33 & 0.51 & 0.27 & 0.17 & 0.02 \\
\hline India & & 2.45 & 0.48 & 0.35 & 0.10 & 0.02 \\
\hline Korea & & 3.47 & 0.71 & 0.44 & 0.20 & -0.14 \\
\hline Malaysia & & 4.06 & 0.69 & 0.30 & 0.07 & -0.16 \\
\hline Mexico & 2.34 & 3.31 & 0.72 & 0.40 & 0.14 & -0.13 \\
\hline Morocco & & 2.77 & 0.06 & 0.25 & 0.08 & -0.18 \\
\hline Nigeria & & 6.69 & 0.45 & 0.09 & -0.06 & -0.12 \\
\hline Philippines & & 7.45 & 0.63 & 0.42 & 0.10 & -0.15 \\
\hline Tunisia & & 2.72 & 0.63 & 0.42 & 0.13 & 0.06 \\
\hline Turkey & 3.48 & 3.62 & 0.38 & 0.14 & 0.06 & -0.12 \\
\hline Uruguay & & 4.94 & 0.63 & 0.50 & 0.27 & -0.01 \\
\hline Developing average & $2.77 / 3.10$ & 4.15 & 0.55 & 0.34 & 0.13 & -0.08 \\
\hline Bulgaria & 4.46 & 6.73 & 0.66 & 0.33 & 0.03 & -0.16 \\
\hline Croatia & 2.28 & 2.63 & 0.52 & 0.21 & 0.06 & -0.02 \\
\hline Czech Republic & 1.91 & 3.20 & 0.76 & 0.58 & 0.39 & 0.32 \\
\hline Estonia & 2.55 & 4.22 & 0.70 & 0.43 & 0.16 & -0.09 \\
\hline Hungary & 1.07 & 3.70 & 0.68 & 0.33 & 0.04 & 0.13 \\
\hline Latvia & 2.14 & 4.95 & 0.58 & 0.30 & 0.18 & 0.04 \\
\hline Lithuania & 4.48 & & 0.31 & 0.10 & 0.07 & 0.37 \\
\hline Poland & 1.29 & 3.28 & 0.86 & 0.61 & 0.36 & 0.13 \\
\hline Romania & 3.84 & 7.65 & 0.68 & 0.45 & 0.37 & 0.29 \\
\hline Russia & 3.33 & 4.74 & 0.81 & 0.53 & 0.27 & 0.07 \\
\hline Slovakia & 1.30 & 2.84 & 0.62 & 0.48 & 0.49 & 0.36 \\
\hline Slovenia & 0.85 & 2.19 & 0.13 & 0.29 & 0.13 & -0.16 \\
\hline Transition average & 2.46 & 4.19 & 0.61 & 0.39 & 0.21 & 0.11 \\
\hline US & 1.74 & 3.70 & 0.85 & 0.65 & 0.41 & 0.21 \\
\hline Canada & 1.39 & 3.79 & 0.78 & 0.51 & 0.27 & 0.04 \\
\hline Japan & 1.53 & 4.07 & 0.78 & 0.59 & 0.38 & 0.19 \\
\hline Germany & 1.69 & 3.06 & 0.67 & 0.46 & 0.35 & 0.23 \\
\hline France & 0.90 & 2.70 & 0.77 & 0.54 & 0.30 & 0.10 \\
\hline UK & 1.54 & 2.85 & 0.55 & 0.37 & 0.20 & 0.07 \\
\hline Italy & 1.70 & 3.58 & 0.80 & 0.52 & 0.22 & -0.04 \\
\hline G7 average & 1.50 & 3.39 & 0.74 & 0.52 & 0.30 & 0.11 \\
\hline Belgium & 2.68 & 2.75 & 0.72 & 0.49 & 0.22 & -0.04 \\
\hline Denmark & 2.30 & 2.24 & 0.26 & 0.05 & 0.00 & 0.13 \\
\hline Greece & 2.85 & 3.04 & 0.64 & 0.36 & 0.17 & -0.01 \\
\hline Ireland & 2.31 & 3.11 & 0.35 & 0.03 & 0.10 & 0.05 \\
\hline Luxembourg & 3.20 & 5.07 & 0.54 & 0.30 & 0.11 & 0.00 \\
\hline Netherlands & 1.79 & 2.27 & 0.32 & 0.09 & 0.11 & 0.06 \\
\hline Portugal & 3.05 & 3.52 & 0.52 & 0.37 & 0.19 & 0.16 \\
\hline Spain & 1.47 & 1.80 & 0.13 & 0.17 & 0.18 & 0.03 \\
\hline EU average & 2.12 & 3.07 & 0.52 & 0.31 & 0.18 & 0.06 \\
\hline
\end{tabular}

Note: All variables refer to the stationary components of output derived using the Hodrick-Prescott Filter. Autocorrelation refers to industrial output for the developing country group, and to real GDP otherwise. 'EU average' includes EU members of G7.

Source: Kydland and Zarazaga (1997) for Argentina (old / new estimates); Agenor et al (2000) for IP in all other developing countries; Alper (2003) for GDP in Mexico and Turkey; Burgoeing and Soto (2000) for GDP in Chile; Fiorito and Kollintzas (1994) for G7 countries; Christodoulakis et al (1995) for EU countries; authors' calculations for transition countries. 
TABLE II

INDUSTRIAL OUTPUT

\begin{tabular}{|c|c|c|c|c|c|c|c|c|c|c|c|c|}
\hline & Bulgaria & Croatia & Czech Rep & Estonia & Hungary & Latvia & Lithuania & Poland & Romania & Russia & Slovakia & Slovenia \\
\hline \multicolumn{13}{|l|}{ Absolute Volatility $^{1}$} \\
\hline$H P$ & 6.73 & 2.63 & 3.31 & 4.22 & 3.93 & 4.95 & & 3.50 & 7.65 & 3.33 & 2.84 & 2.19 \\
\hline$F D$ & 5.36 & 2.58 & 2.81 & 3.30 & 2.13 & 3.97 & & 3.58 & 4.14 & 2.25 & 2.42 & 1.70 \\
\hline$T P$ & 7.84 & 2.77 & 3.70 & 4.24 & 4.72 & 5.13 & & 3.43 & 9.69 & 2.93 & 3.27 & 2.34 \\
\hline \multicolumn{13}{|l|}{ Relative Volatility $^{2}$} \\
\hline$H P$ & 1.51 & 1.15 & 1.73 & 1.65 & 3.69 & 2.31 & & 2.72 & 1.99 & 1.11 & 2.18 & 2.56 \\
\hline$F D$ & 1.40 & 1.14 & 2.07 & 1.64 & 2.56 & 2.00 & & 4.60 & 1.32 & 1.49 & 2.09 & 1.50 \\
\hline$T P$ & 1.79 & 1.16 & 1.66 & 1.57 & 4.13 & 2.49 & & 3.69 & 2.19 & 1.24 & 2.24 & 2.67 \\
\hline \multicolumn{13}{|l|}{ Cyclicality $^{3}$} \\
\hline$H P$ & 0.33 & 0.86 & 0.43 & 0.75 & 0.75 & 0.70 & & 0.74 & 0.80 & 0.74 & 0.48 & 0.26 \\
\hline$F D$ & 0.46 & 0.71 & 0.01 & 0.69 & 0.65 & 0.49 & & 0.50 & 0.41 & 0.78 & 0.31 & 0.09 \\
\hline$T P$ & 0.25 & 0.88 & 0.54 & 0.76 & 0.81 & 0.68 & & 0.68 & 0.83 & 0.84 & 0.54 & 0.22 \\
\hline \multicolumn{13}{|l|}{ Leads and Lags ${ }^{4}$} \\
\hline-4 & -0.42 & 0.00 & -0.20 & -0.02 & 0.23 & -0.14 & & -0.03 & 0.32 & -0.18 & 0.44 & -0.29 \\
\hline-3 & -0.22 & 0.04 & 0.09 & 0.34 & 0.39 & -0.02 & & 0.24 & 0.48 & -0.03 & 0.31 & -0.34 \\
\hline-2 & -0.07 & 0.15 & 0.21 & 0.37 & 0.54 & 0.18 & & 0.49 & 0.60 & 0.17 & 0.32 & -0.10 \\
\hline-1 & 0.04 & 0.48 & 0.31 & 0.55 & 0.67 & 0.55 & & 0.62 & 0.67 & 0.49 & 0.43 & 0.06 \\
\hline+1 & 0.35 & 0.57 & 0.52 & 0.55 & 0.58 & 0.66 & & 0.62 & 0.79 & 0.62 & 0.25 & 0.38 \\
\hline+2 & 0.28 & 0.28 & 0.54 & 0.28 & 0.37 & 0.41 & & 0.41 & 0.64 & 0.47 & -0.02 & 0.33 \\
\hline+3 & 0.17 & 0.29 & 0.42 & -0.02 & 0.13 & 0.11 & & 0.16 & 0.53 & 0.26 & -0.20 & 0.35 \\
\hline \multirow{2}{*}{$\begin{array}{r}+4 \\
\text { Persistence }^{5}\end{array}$} & 0.10 & -0.04 & 0.42 & -0.20 & 0.00 & -0.24 & & -0.02 & 0.40 & 0.11 & -0.39 & 0.13 \\
\hline & 0.68 & 0.51 & 0.62 & 0.70 & 0.83 & 0.68 & & 0.49 & 0.87 & 0.65 & 0.64 & 0.71 \\
\hline
\end{tabular}

Notes: $\quad 1$ 'Absolute Volatility' is measured as the standard deviation of industrial output.

2 'Relative Volatility' is measured as the ratio of the standard deviation of industrial output and real GDP.

3 'Cyclicality' is measured as the contemporaneous correlation between of industrial output and real GDP.

4 'Lead (lag)' is measured as the correlation between leads (lags) in HP-filtered industrial output and real GDP.

5 'Persistence' is measured as the $\mathrm{AR}(1)$ coefficient in HP-filtered industrial output.

6 Bold figures indicate the largest correlation coefficient (in absolute value) in HP-filtered industrial output.

7 Data are at the quarterly frequency, unless otherwise indicated 1993:1 to 2002:4. All variables are de-seasonalized and de-trended. The alternative de-trending methods include the Hodrick-Prescott filter $(H P), \log$ first-differencing $(F D)$ and fitting a quadratic time-trend polynomial $(T P)$. 
TABLE III

PRIVATE CONSUMPTION

\begin{tabular}{|c|c|c|c|c|c|c|c|c|c|c|c|c|}
\hline & Bulgaria & Croatia & Czech Rep & Estonia & Hungary & Latvia & Lithuania & Poland & Romania & Russia & Slovakia & Slovenia \\
\hline \multicolumn{13}{|l|}{ Absolute Volatility $^{1}$} \\
\hline$H P$ & 9.37 & & 2.25 & 3.06 & 2.72 & 3.46 & 6.96 & 1.37 & 6.22 & 5.40 & 2.68 & \\
\hline$F D$ & 9.02 & & 2.08 & 2.73 & 2.09 & 4.26 & 9.85 & 1.25 & 5.48 & 3.60 & 2.57 & \\
\hline$T P$ & 9.40 & & 2.71 & 3.19 & 1.96 & 3.58 & 7.21 & 0.97 & 7.11 & 5.26 & 2.91 & \\
\hline \multicolumn{13}{|l|}{ Relative Volatility $^{2}$} \\
\hline$H P$ & 2.10 & & 1.18 & 1.20 & 2.55 & 1.62 & 1.55 & 1.06 & 1.62 & 1.62 & 2.06 & \\
\hline$F D$ & 2.37 & & 1.53 & 1.36 & 2.52 & 2.14 & 1.95 & 1.61 & 1.75 & 1.60 & 2.22 & \\
\hline$T P$ & 2.15 & & 1.22 & 1.18 & 1.71 & 1.73 & 1.57 & 1.05 & 1.61 & 1.79 & 2.00 & \\
\hline \multicolumn{13}{|l|}{ Cyclicality $^{3}$} \\
\hline$H P$ & 0.80 & & 0.65 & 0.71 & 0.48 & 0.18 & 0.08 & 0.48 & 0.67 & 0.27 & 0.49 & \\
\hline$F D$ & 0.76 & & 0.41 & 0.27 & 0.34 & -0.03 & -0.05 & 0.19 & 0.07 & 0.36 & 0.35 & \\
\hline \multirow{2}{*}{\multicolumn{13}{|c|}{ Leads and Lags ${ }^{4}$}} \\
\hline & & & & & & & & & & & & \\
\hline-4 & -0.30 & & 0.49 & -0.03 & -0.02 & -0.08 & -0.15 & 0.61 & -0.06 & -0.42 & 0.00 & \\
\hline-3 & -0.24 & & 0.48 & 0.27 & -0.10 & 0.03 & 0.59 & 0.76 & 0.19 & -0.34 & 0.10 & \\
\hline-2 & -0.05 & & 0.53 & 0.49 & 0.24 & 0.34 & 0.07 & 0.79 & 0.49 & -0.18 & 0.18 & \\
\hline-1 & 0.32 & & 0.55 & 0.60 & 0.34 & 0.32 & -0.04 & 0.70 & 0.64 & -0.03 & 0.18 & \\
\hline+1 & 0.72 & & 0.49 & 0.64 & 0.28 & 0.17 & 0.57 & 0.30 & 0.66 & 0.47 & 0.54 & \\
\hline+2 & 0.42 & & 0.55 & 0.46 & 0.15 & 0.09 & 0.36 & 0.21 & 0.55 & 0.47 & 0.57 & \\
\hline+3 & 0.09 & & 0.47 & 0.11 & 0.08 & -0.15 & -0.11 & 0.04 & 0.55 & 0.48 & 0.75 & \\
\hline \multirow{2}{*}{$\begin{array}{r}+4 \\
\text { Persistence }^{5}\end{array}$} & 0.01 & & 0.27 & 0.00 & 0.16 & -0.32 & 0.34 & -0.22 & 0.36 & 0.34 & 0.54 & \\
\hline & 0.56 & & 0.61 & 0.61 & 0.72 & 0.25 & -0.09 & 0.62 & 0.63 & 0.71 & 0.56 & \\
\hline
\end{tabular}

Notes: $\quad 1$ 'Absolute Volatility' is measured as the standard deviation of private consumption.

2 'Relative Volatility' is measured as the ratio of the standard deviation of private consumption and real GDP.

3 'Cyclicality' is measured as the contemporaneous correlation between of private consumption and real GDP.

4 'Lead (lag)' is measured as the correlation between leads (lags) in HP-filtered private consumption and real GDP.

5 'Persistence' is measured as the AR(1) coefficient in HP-filtered private consumption.

6 Bold figures indicate the largest correlation coefficient (in absolute value) in HP-filtered private consumption.

7 Data are at the quarterly frequency, unless otherwise indicated 1993:1 to 2002:4. All variables are de-seasonalized and de-trended. The alternative de-trending methods include the Hodrick-Prescott filter $(H P), \log$ first-differencing $(F D)$ and fitting a quadratic time-trend polynomial $(T P)$. 
TABLE IV

INVESTMENT

\begin{tabular}{|c|c|c|c|c|c|c|c|c|c|c|c|c|}
\hline & Bulgaria & Croatia & Czech Rep & Estonia & Hungary & Latvia & Lithuania & Poland & Romania & Russia & Slovakia & Slovenia \\
\hline \multicolumn{13}{|l|}{ Absolute Volatility $^{1}$} \\
\hline$H P$ & 17.09 & & 5.77 & 7.02 & 3.02 & 13.57 & 11.55 & 8.33 & 13.56 & 14.71 & 11.00 & \\
\hline$F D$ & 17.84 & & 3.61 & 6.45 & 3.36 & 19.88 & 10.52 & 6.52 & 14.87 & 11.01 & 8.79 & \\
\hline$T P$ & 17.39 & & 8.42 & 7.35 & 2.94 & 14.01 & 12.41 & 7.15 & 15.15 & 14.90 & 11.90 & \\
\hline \multicolumn{13}{|l|}{ Relative Volatility $^{2}$} \\
\hline$H P$ & 3.83 & & 3.02 & 2.75 & 2.83 & 6.34 & 2.58 & 6.46 & 3.53 & 4.41 & 8.47 & \\
\hline$F D$ & 4.69 & & 2.65 & 3.21 & 4.05 & 10.00 & 2.09 & 8.38 & 4.73 & 4.90 & 7.59 & \\
\hline$T P$ & 3.99 & & 3.79 & 2.73 & 2.57 & 6.79 & 2.70 & 7.70 & 3.43 & 5.08 & 8.18 & \\
\hline \multicolumn{13}{|l|}{ Cyclicality $^{3}$} \\
\hline$H P$ & 0.45 & & 0.67 & 0.67 & 0.47 & 0.36 & 0.63 & 0.83 & 0.71 & 0.60 & 0.43 & \\
\hline$F D$ & 0.23 & & 0.59 & 0.28 & 0.28 & 0.38 & 0.31 & 0.60 & 0.67 & 0.35 & -0.03 & \\
\hline$T P$ & 0.44 & & 0.68 & 0.67 & 0.59 & 0.44 & 0.66 & 0.75 & 0.77 & 0.62 & 0.48 & \\
\hline \multicolumn{13}{|l|}{ Leads and Lags ${ }^{4}$} \\
\hline-4 & -0.05 & & 0.64 & -0.07 & 0.38 & -0.04 & 0.32 & 0.16 & 0.35 & -0.02 & 0.15 & \\
\hline-3 & 0.28 & & 0.64 & 0.16 & 0.37 & -0.20 & 0.17 & 0.32 & 0.49 & 0.06 & 0.23 & \\
\hline-2 & 0.27 & & 0.59 & 0.35 & 0.30 & 0.14 & 0.28 & 0.48 & 0.57 & 0.10 & 0.39 & \\
\hline-1 & 0.28 & & 0.58 & 0.53 & 0.51 & -0.04 & 0.55 & 0.65 & 0.55 & 0.33 & 0.40 & \\
\hline+1 & 0.46 & & 0.52 & 0.61 & 0.15 & 0.35 & 0.32 & 0.80 & 0.27 & 0.80 & 0.53 & \\
\hline+2 & 0.47 & & 0.31 & 0.40 & -0.24 & 0.26 & 0.13 & 0.67 & 0.21 & 0.72 & 0.55 & \\
\hline+3 & 0.40 & & 0.11 & 0.25 & -0.19 & 0.27 & 0.39 & 0.42 & 0.36 & 0.62 & 0.64 & \\
\hline \multirow{2}{*}{$\begin{array}{r}+4 \\
\text { Persistence }^{5}\end{array}$} & 0.18 & & -0.04 & 0.07 & -0.32 & 0.18 & 0.42 & 0.30 & 0.27 & 0.39 & 0.39 & \\
\hline & 0.48 & & 0.71 & 0.59 & 0.39 & -0.08 & 0.57 & 0.71 & 0.37 & 0.65 & 0.70 & \\
\hline
\end{tabular}

Notes: $\quad 1$ 'Absolute Volatility' is measured as the standard deviation of investment.

2 'Relative Volatility' is measured as the ratio of the standard deviation of investment and real GDP.

3 'Cyclicality' is measured as the contemporaneous correlation between of investment and real GDP.

4 'Lead (lag)' is measured as the correlation between the leads (lags) in HP-filtered investment and real GDP.

5 'Persistence' is measured as the AR(1) coefficient in HP-filtered investment.

6 Bold figures indicate the largest correlation coefficient (in absolute value) in HP-filtered investment.

7 Data are at the quarterly frequency, unless otherwise indicated 1993:1 to 2002:4. All variables are de-seasonalized and de-trended. The alternative de-trending methods include the Hodrick-Prescott filter $(H P), \log$ first-differencing $(F D)$ and fitting a quadratic time-trend polynomial $(T P)$. 
TABLE V

GOVERNMENT CONSUMPTION

\begin{tabular}{|c|c|c|c|c|c|c|c|c|c|c|c|c|}
\hline & Bulgaria & Croatia & Czech Rep & Estonia & Hungary & Latvia & Lithuania & Poland & Romania & Russia & Slovakia & Slovenia \\
\hline \multicolumn{13}{|l|}{ Absolute Volatility $^{1}$} \\
\hline$H P$ & 16.24 & & 4.00 & 4.10 & 6.14 & 6.44 & 10.28 & 4.84 & 6.98 & 11.70 & 6.17 & \\
\hline$F D$ & 14.09 & & 3.77 & 4.59 & 3.93 & 8.85 & 11.96 & 5.82 & 6.39 & 8.25 & 5.83 & \\
\hline$T P$ & 17.06 & & 4.46 & 4.27 & 5.36 & 6.31 & 11.00 & 5.00 & 7.28 & 11.79 & 6.72 & \\
\hline \multicolumn{13}{|l|}{ Relative Volatility ${ }^{2}$} \\
\hline$H P$ & 3.64 & & 2.09 & 1.61 & 5.76 & 3.01 & 2.29 & 3.75 & 1.82 & 3.51 & 4.74 & \\
\hline$F D$ & 3.70 & & 2.77 & 2.29 & 4.73 & 4.45 & 2.37 & 7.48 & 2.04 & 3.67 & 5.03 & \\
\hline$T P$ & 3.91 & & 2.01 & 1.58 & 4.68 & 3.05 & 2.39 & 5.38 & 1.65 & 4.02 & 4.62 & \\
\hline \multicolumn{13}{|l|}{ Cyclicality $^{3}$} \\
\hline$H P$ & 0.73 & & 0.26 & -0.17 & 0.01 & 0.15 & 0.55 & 0.01 & 0.38 & 0.28 & 0.56 & \\
\hline$F D$ & 0.65 & & 0.13 & 0.14 & 0.11 & 0.32 & 0.45 & -0.16 & -0.11 & 0.18 & 0.10 & \\
\hline$T P$ & 0.67 & & 0.44 & -0.20 & -0.21 & 0.08 & 0.60 & 0.12 & 0.43 & 0.25 & 0.65 & \\
\hline \multicolumn{13}{|l|}{ Leads and Lags ${ }^{4}$} \\
\hline-4 & -0.02 & & 0.44 & -0.26 & 0.11 & -0.12 & -0.04 & -0.50 & 0.42 & -0.24 & 0.20 & \\
\hline-3 & 0.20 & & 0.42 & -0.28 & -0.12 & -0.25 & -0.39 & -0.30 & 0.54 & -0.05 & 0.36 & \\
\hline-2 & 0.33 & & 0.52 & -0.18 & -0.12 & -0.26 & 0.01 & -0.17 & 0.59 & 0.12 & 0.41 & \\
\hline-1 & 0.55 & & 0.27 & -0.18 & -0.09 & -0.42 & 0.30 & 0.00 & 0.62 & 0.17 & 0.42 & \\
\hline+1 & 0.52 & & 0.28 & -0.22 & -0.14 & 0.33 & 0.06 & 0.12 & 0.23 & 0.41 & 0.63 & \\
\hline+2 & 0.29 & & 0.36 & -0.26 & -0.23 & 0.22 & 0.32 & 0.29 & 0.05 & 0.55 & 0.55 & \\
\hline+3 & -0.09 & & 0.39 & -0.20 & -0.27 & 0.41 & 0.40 & 0.26 & -0.16 & 0.60 & 0.50 & \\
\hline \multirow{2}{*}{$\begin{array}{r}+4 \\
\text { Persistence }^{5}\end{array}$} & -0.33 & & 0.23 & 0.00 & -0.25 & 0.32 & 0.36 & 0.13 & -0.29 & 0.56 & 0.31 & \\
\hline & 0.64 & & 0.52 & 0.36 & 0.82 & 0.09 & 0.28 & 0.30 & 0.59 & 0.71 & 0.57 & \\
\hline
\end{tabular}

Notes: $\quad 1$ 'Absolute Volatility' is measured as the standard deviation of government consumption.

2 'Relative Volatility' is measured as the ratio of the standard deviation of government consumption and real GDP.

3 'Cyclicality' is measured as the contemporaneous correlation between of government consumption and real GDP.

4 'Lead (lag)' is measured as the correlation between the leads (lags) in HP-filtered government consumption and real GDP.

5 'Persistence' is measured as the AR(1) coefficient in HP-filtered government consumption.

6 Bold figures indicate the largest correlation coefficient (in absolute value) in HP-filtered government consumption.

7 Data are at the quarterly frequency, unless otherwise indicated 1993:1 to 2002:4. All variables are de-seasonalized and de-trended. The alternative de-trending methods include the Hodrick-Prescott filter $(H P), \log$ first-differencing $(F D)$ and fitting a quadratic time-trend polynomial $(T P)$. 
TABLE VI

NET EXPORTS TO GDP

\begin{tabular}{|c|c|c|c|c|c|c|c|c|c|c|c|c|}
\hline & Bulgaria & Croatia & Czech Rep & Estonia & Hungary & Latvia & Lithuania & Poland & Romania & Russia & Slovakia & Slovenia \\
\hline \multicolumn{13}{|l|}{ Absolute Volatility $^{1}$} \\
\hline$H P$ & 3.89 & 3.04 & 2.28 & 4.79 & 1.56 & 2.01 & 3.65 & 1.31 & 2.10 & 5.00 & 3.41 & 1.74 \\
\hline$F D$ & 4.95 & 2.85 & 1.62 & 5.29 & 1.47 & 2.36 & 4.43 & 0.88 & 2.36 & 2.98 & 3.65 & 2.54 \\
\hline$T P$ & 4.14 & 3.19 & 2.46 & 5.11 & 1.64 & 2.03 & 3.72 & 0.94 & 2.24 & 5.54 & 3.57 & 1.73 \\
\hline \multicolumn{13}{|l|}{ Relative Volatility $^{2}$} \\
\hline$H P$ & 0.87 & 1.33 & 1.19 & 1.88 & 1.47 & 0.94 & 0.81 & 1.01 & 0.55 & 1.50 & 2.63 & 2.03 \\
\hline$F D$ & 1.30 & 1.26 & 1.19 & 2.64 & 1.77 & 1.19 & 0.88 & 1.13 & 0.75 & 1.33 & 3.15 & 2.23 \\
\hline$T P$ & 0.95 & 1.34 & 1.11 & 1.90 & 1.44 & 0.99 & 0.81 & 1.02 & 0.51 & 1.89 & 2.45 & 1.97 \\
\hline \multicolumn{13}{|l|}{ Cyclicality $^{3}$} \\
\hline$H P$ & -0.08 & -0.61 & -0.74 & -0.27 & -0.55 & -0.34 & -0.16 & -0.68 & -0.47 & 0.14 & -0.23 & -0.46 \\
\hline$F D$ & 0.04 & -0.51 & -0.14 & 0.05 & -0.37 & 0.02 & -0.10 & -0.56 & -0.09 & -0.07 & -0.02 & -0.50 \\
\hline$T P$ & -0.16 & -0.63 & -0.79 & -0.27 & -0.61 & -0.28 & -0.23 & -0.27 & -0.59 & 0.26 & -0.25 & -0.45 \\
\hline \multicolumn{13}{|l|}{ Leads and Lags ${ }^{4}$} \\
\hline-4 & 0.08 & -0.28 & -0.34 & -0.21 & -0.31 & -0.02 & 0.10 & -0.66 & -0.19 & 0.63 & 0.05 & -0.07 \\
\hline-3 & -0.05 & -0.53 & -0.46 & -0.32 & -0.28 & -0.10 & -0.33 & -0.74 & -0.28 & 0.64 & -0.03 & -0.03 \\
\hline-2 & -0.17 & -0.63 & -0.69 & -0.32 & -0.37 & -0.19 & -0.31 & -0.78 & -0.45 & 0.61 & -0.17 & -0.12 \\
\hline-1 & -0.08 & -0.59 & -0.78 & -0.41 & -0.54 & -0.25 & -0.27 & -0.78 & -0.55 & 0.43 & -0.13 & 0.03 \\
\hline+1 & -0.25 & -0.18 & -0.63 & -0.25 & -0.16 & -0.40 & -0.10 & -0.51 & -0.36 & -0.15 & -0.35 & -0.01 \\
\hline+2 & -0.22 & 0.02 & -0.54 & -0.01 & 0.02 & -0.15 & 0.07 & -0.22 & -0.28 & -0.27 & -0.47 & -0.18 \\
\hline+3 & -0.25 & 0.18 & -0.32 & 0.07 & -0.02 & -0.12 & -0.17 & 0.09 & -0.27 & -0.36 & -0.42 & -0.08 \\
\hline \multirow{2}{*}{$\begin{array}{r}+4 \\
\text { Persistence }^{5}\end{array}$} & -0.25 & 0.32 & -0.10 & 0.20 & -0.14 & 0.05 & -0.45 & 0.32 & -0.22 & -0.48 & -0.28 & 0.08 \\
\hline & -0.10 & 0.58 & 0.76 & 0.42 & 0.52 & 0.34 & 0.26 & 0.83 & 0.37 & 0.83 & 0.44 & -0.04 \\
\hline
\end{tabular}

Notes: $\quad 1$ 'Absolute Volatility' is measured as the standard deviation of net exports to GDP.

2 'Relative Volatility' is measured as the ratio of the standard deviation of net exports to GDP and real GDP.

3 'Cyclicality' is measured as the contemporaneous correlation between of net exports to GDP and real GDP.

4 'Lead (lag)' is measured as the correlation between the leads (lags) in HP-filtered net exports to GDP and real GDP.

5 'Persistence' is measured as the AR(1) coefficient in HP-filtered net exports to GDP.

6 Bold figures indicate the largest correlation coefficient (in absolute value) in HP-filtered net exports to GDP.

7 Data are at the quarterly frequency, unless otherwise indicated 1993:1 to 2002:4. All variables are de-seasonalized and de-trended. The alternative de-trending methods include the Hodrick-Prescott filter $(H P), \log$ first-differencing $(F D)$ and fitting a quadratic time-trend polynomial $(T P)$. 
TABLE VII

REAL IMPORTS

\begin{tabular}{|c|c|c|c|c|c|c|c|c|c|c|c|c|}
\hline & Bulgaria & Croatia & Czech Rep & Estonia & Hungary & Latvia & Lithuania & Poland & Romania & Russia & Slovakia & Slovenia \\
\hline \multicolumn{13}{|l|}{ Absolute Volatility $^{1}$} \\
\hline$H P$ & 17.80 & 7.36 & 8.33 & 11.18 & 7.89 & 6.53 & 14.16 & 5.50 & 13.79 & 7.46 & 7.75 & 3.76 \\
\hline$F D$ & 15.51 & 7.43 & 5.80 & 8.10 & 4.83 & 5.75 & 10.20 & 4.06 & 12.12 & 7.76 & 8.85 & 5.18 \\
\hline$T P$ & 18.39 & 7.54 & 8.86 & 11.16 & 9.62 & 6.95 & 14.42 & 5.53 & 16.05 & 7.08 & 7.82 & 3.84 \\
\hline \multicolumn{13}{|l|}{ Relative Volatility $^{2}$} \\
\hline$H P$ & 3.99 & 3.23 & 4.36 & 4.38 & 7.41 & 3.05 & 3.16 & 4.26 & 3.59 & 2.24 & 5.96 & 4.40 \\
\hline$F D$ & 4.08 & 3.30 & 4.26 & 4.04 & 5.81 & 2.89 & 2.02 & 5.22 & 3.86 & 3.46 & 7.64 & 4.56 \\
\hline$T P$ & 4.22 & 3.16 & 3.98 & 4.14 & 8.40 & 3.37 & 3.14 & 5.96 & 3.64 & 2.41 & 5.37 & 4.38 \\
\hline \multicolumn{13}{|l|}{ Cyclicality $^{3}$} \\
\hline$H P$ & 0.50 & 0.57 & 0.67 & 0.41 & 0.46 & 0.66 & 0.45 & 0.73 & 0.73 & 0.52 & 0.11 & 0.64 \\
\hline$F D$ & 0.11 & 0.50 & 0.34 & 0.14 & 0.57 & 0.32 & 0.23 & 0.60 & 0.14 & 0.53 & 0.04 & 0.71 \\
\hline$T P$ & 0.50 & 0.58 & 0.70 & 0.46 & 0.59 & 0.60 & 0.47 & 0.49 & 0.79 & 0.45 & 0.14 & 0.65 \\
\hline \multicolumn{13}{|l|}{ Leads and Lags ${ }^{4}$} \\
\hline-4 & -0.53 & 0.33 & 0.46 & -0.06 & 0.32 & -0.05 & 0.45 & 0.39 & 0.32 & 0.11 & 0.17 & -0.30 \\
\hline-3 & -0.57 & 0.47 & 0.51 & 0.10 & 0.43 & 0.06 & 0.55 & 0.59 & 0.64 & 0.16 & -0.05 & -0.16 \\
\hline-2 & -0.16 & 0.52 & 0.62 & 0.31 & 0.49 & 0.28 & 0.55 & 0.72 & 0.63 & 0.29 & 0.07 & 0.07 \\
\hline-1 & 0.32 & 0.46 & 0.66 & 0.43 & 0.52 & 0.53 & 0.40 & 0.76 & 0.76 & 0.43 & -0.01 & -0.07 \\
\hline+1 & 0.61 & 0.20 & 0.48 & 0.46 & 0.21 & 0.64 & 0.29 & 0.53 & 0.67 & 0.29 & 0.25 & 0.07 \\
\hline+2 & 0.45 & -0.04 & 0.25 & 0.27 & 0.05 & 0.36 & 0.16 & 0.24 & 0.55 & -0.10 & 0.27 & 0.34 \\
\hline+3 & 0.29 & -0.22 & -0.02 & 0.12 & -0.09 & 0.16 & -0.01 & -0.08 & 0.37 & -0.23 & 0.27 & 0.35 \\
\hline \multicolumn{12}{|l|}{ Persistence $^{5}$} & 0.10 \\
\hline & 0.64 & 0.51 & 0.70 & 0.75 & 0.61 & 0.62 & 0.76 & 0.58 & 0.62 & 0.51 & 0.35 & 0.08 \\
\hline
\end{tabular}

Notes: $\quad 1$ 'Absolute Volatility' is measured as the standard deviation of real imports.

2 'Relative Volatility' is measured as the ratio of the standard deviation of real imports and real GDP.

3 'Cyclicality' is measured as the contemporaneous correlation between of real imports and real GDP.

4 'Lead (lag)' is measured as the correlation between the leads (lags) in HP-filtered real imports and real GDP.

5 'Persistence' is measured as the AR(1) coefficient in HP-filtered real imports.

6 Bold figures indicate the largest correlation coefficient (in absolute value) in HP-filtered real imports.

7 Data are at the quarterly frequency, unless otherwise indicated 1993:1 to 2002:4. All variables are de-seasonalized and de-trended. The alternative de-trending methods include the Hodrick-Prescott filter $(H P), \log$ first-differencing $(F D)$ and fitting a quadratic time-trend polynomial $(T P)$. 
TABLE VIII

REAL EXPORTS

\begin{tabular}{|c|c|c|c|c|c|c|c|c|c|c|c|c|}
\hline & Bulgaria & Croatia & Czech Rep & Estonia & Hungary & Latvia & Lithuania & Poland & Romania & Russia & Slovakia & Slovenia \\
\hline \multicolumn{13}{|l|}{ Absolute Volatility ${ }^{1}$} \\
\hline$H P$ & 19.34 & 5.80 & 6.42 & 10.30 & 6.82 & 7.80 & 14.06 & 4.87 & 12.61 & 17.90 & 7.31 & 3.71 \\
\hline$F D$ & 18.87 & 6.78 & 5.05 & 7.10 & 4.63 & 6.40 & 11.19 & 4.58 & 10.03 & 10.60 & 8.20 & 3.17 \\
\hline$T P$ & 20.70 & 6.19 & 6.52 & 10.83 & 7.59 & 7.68 & 13.44 & 5.09 & 14.93 & 20.93 & 7.54 & 3.77 \\
\hline \multicolumn{13}{|l|}{ Relative Volatility $^{2}$} \\
\hline$H P$ & 4.33 & 2.54 & 3.35 & 4.04 & 6.40 & 3.64 & 3.14 & 3.77 & 3.28 & 5.37 & 5.62 & 4.34 \\
\hline$F D$ & 4.96 & 3.01 & 3.71 & 3.54 & 5.57 & 3.22 & 2.22 & 5.88 & 3.19 & 4.72 & 7.08 & 2.79 \\
\hline$T P$ & 4.75 & 2.59 & 2.93 & 4.02 & 6.63 & 3.72 & 2.92 & 5.49 & 3.39 & 7.13 & 5.18 & 4.29 \\
\hline \multicolumn{13}{|l|}{ Cyclicality $^{3}$} \\
\hline$H P$ & 0.27 & -0.37 & 0.32 & 0.46 & 0.46 & 0.72 & 0.35 & 0.11 & 0.58 & 0.23 & -0.13 & 0.22 \\
\hline$F D$ & -0.14 & -0.13 & 0.27 & 0.24 & 0.24 & 0.55 & 0.03 & 0.12 & -0.01 & 0.22 & -0.01 & 0.35 \\
\hline$T P$ & 0.27 & -0.43 & 0.26 & 0.51 & 0.51 & 0.69 & 0.35 & 0.50 & 0.62 & 0.32 & -0.13 & 0.26 \\
\hline \multicolumn{13}{|l|}{ Leads and Lags ${ }^{4}$} \\
\hline-4 & -0.53 & 0.14 & 0.16 & -0.20 & 0.07 & 0.34 & 0.59 & -0.54 & 0.36 & 0.61 & 0.23 & -0.39 \\
\hline-3 & -0.59 & -0.15 & 0.26 & 0.01 & 0.15 & 0.36 & 0.54 & -0.25 & 0.62 & 0.65 & -0.11 & -0.21 \\
\hline-2 & -0.16 & -0.34 & 0.32 & 0.31 & 0.22 & 0.20 & 0.55 & -0.05 & 0.55 & 0.65 & -0.10 & -0.05 \\
\hline-1 & 0.22 & -0.47 & 0.29 & 0.42 & 0.24 & 0.43 & 0.33 & 0.04 & 0.59 & 0.51 & -0.16 & -0.05 \\
\hline+1 & 0.44 & -0.15 & 0.18 & 0.46 & 0.26 & 0.57 & 0.28 & 0.11 & 0.60 & -0.12 & -0.07 & 0.08 \\
\hline+2 & 0.36 & -0.12 & -0.05 & 0.35 & 0.19 & 0.27 & 0.23 & 0.11 & 0.48 & -0.35 & -0.17 & 0.19 \\
\hline+3 & 0.33 & -0.14 & -0.25 & 0.21 & -0.03 & -0.02 & -0.17 & 0.02 & 0.27 & -0.45 & -0.13 & 0.31 \\
\hline \multirow{2}{*}{ Persistence $^{5}$} & 0.30 & -0.21 & -0.38 & 0.04 & -0.11 & -0.27 & -0.36 & -0.13 & 0.04 & -0.53 & -0.24 & 0.19 \\
\hline & 0.53 & 0.33 & 0.69 & 0.77 & 0.77 & 0.65 & 0.71 & 0.56 & 0.70 & 0.81 & 0.39 & 0.64 \\
\hline
\end{tabular}

Notes: $\quad 1$ 'Absolute Volatility' is measured as the standard deviation of real exports.

2 'Relative Volatility' is measured as the ratio of the standard deviation of real exports and real GDP.

3 'Cyclicality' is measured as the contemporaneous correlation between of real exports and real GDP.

4 'Lead (lag)' is measured as the correlation between the leads (lags) in HP-filtered real exports and real GDP.

5 'Persistence' is measured as the AR(1) coefficient in HP-filtered real exports.

6 Bold figures indicate the largest correlation coefficient (in absolute value) in HP-filtered real exports.

7 Data are at the quarterly frequency, unless otherwise indicated 1993:1 to 2002:4. All variables are de-seasonalized and de-trended. The alternative de-trending methods include the Hodrick-Prescott filter $(H P), \log$ first-differencing $(F D)$ and fitting a quadratic time-trend polynomial $(T P)$. 
TABLE IX

EMPLOYMENT

\begin{tabular}{|c|c|c|c|c|c|c|c|c|c|c|c|c|}
\hline & Bulgaria & Croatia & Czech Rep & Estonia & Hungary & Latvia & Lithuania & Poland & Romania & Russia & Slovakia & Slovenia \\
\hline \multicolumn{13}{|l|}{ Absolute Volatility ${ }^{1}$} \\
\hline$H P$ & 7.32 & 3.62 & 0.79 & 1.38 & 1.93 & 2.78 & 6.38 & 1.18 & 3.03 & 3.42 & 2.12 & 0.56 \\
\hline$F D$ & 4.15 & 3.01 & 0.35 & 1.06 & 1.08 & 1.88 & 4.20 & 0.75 & 1.94 & 4.24 & 1.35 & 0.44 \\
\hline$T P$ & 8.23 & 3.70 & 1.08 & 1.27 & 2.72 & 2.79 & 6.99 & 1.05 & 3.46 & 3.60 & 2.54 & 0.56 \\
\hline \multicolumn{13}{|l|}{ Relative Volatility $^{2}$} \\
\hline$H P$ & 1.64 & 1.59 & 0.42 & 0.54 & 1.81 & 1.30 & 1.43 & 0.92 & 0.79 & 1.03 & 1.63 & 0.65 \\
\hline$F D$ & 1.09 & 1.34 & 0.58 & 0.53 & 1.30 & 0.95 & 0.83 & 0.96 & 0.62 & 1.89 & 1.17 & 0.39 \\
\hline$T P$ & 1.89 & 1.55 & 0.36 & 0.47 & 2.38 & 1.35 & 1.52 & 1.13 & 0.78 & 1.23 & 1.74 & 0.64 \\
\hline \multicolumn{13}{|l|}{ Cyclicality $^{3}$} \\
\hline$H P$ & -0.05 & 0.28 & 0.60 & 0.46 & 0.57 & 0.75 & 0.45 & 0.45 & 0.38 & 0.40 & 0.60 & 0.05 \\
\hline$F D$ & -0.05 & 0.24 & 0.14 & 0.12 & 0.23 & 0.48 & 0.37 & 0.29 & -0.05 & 0.05 & 0.36 & -0.20 \\
\hline$T P$ & -0.13 & 0.35 & 0.68 & 0.41 & 0.64 & 0.73 & 0.45 & 0.02 & 0.49 & 0.42 & 0.67 & 0.27 \\
\hline \multicolumn{13}{|l|}{ Leads and Lags ${ }^{4}$} \\
\hline-4 & -0.29 & 0.35 & 0.21 & -0.09 & 0.40 & 0.34 & -0.07 & 0.61 & -0.23 & 0.37 & 0.58 & -0.10 \\
\hline-3 & -0.21 & 0.24 & 0.23 & 0.17 & 0.49 & 0.47 & -0.15 & 0.52 & -0.06 & 0.35 & 0.57 & 0.07 \\
\hline-2 & -0.15 & 0.28 & 0.25 & 0.29 & 0.53 & 0.38 & -0.11 & 0.47 & 0.10 & 0.37 & 0.59 & -0.09 \\
\hline-1 & -0.09 & 0.28 & 0.29 & 0.40 & 0.56 & 0.59 & 0.09 & 0.45 & 0.30 & 0.43 & 0.61 & 0.04 \\
\hline+1 & 0.02 & 0.15 & 0.36 & 0.47 & 0.51 & 0.62 & 0.42 & 0.43 & 0.48 & 0.37 & 0.38 & 0.27 \\
\hline+2 & 0.34 & -0.13 & 0.38 & 0.57 & 0.31 & 0.42 & 0.35 & 0.35 & 0.52 & 0.31 & 0.28 & 0.48 \\
\hline+3 & 0.64 & -0.12 & 0.37 & 0.40 & 0.08 & 0.12 & 0.39 & 0.26 & 0.45 & 0.06 & 0.07 & 0.22 \\
\hline \multirow{2}{*}{$\begin{array}{r}+4 \\
\text { Persistence }^{5}\end{array}$} & 0.79 & 0.02 & 0.35 & 0.22 & -0.09 & -0.17 & 0.47 & 0.10 & 0.49 & -0.25 & -0.11 & 0.33 \\
\hline & 0.86 & 0.67 & 0.96 & 0.75 & 0.88 & 0.79 & 0.83 & 0.89 & 0.81 & 0.33 & 0.80 & 0.73 \\
\hline
\end{tabular}

Notes: $\quad 1$ 'Absolute Volatility' is measured as the standard deviation of employment.

2 'Relative Volatility' is measured as the ratio of the standard deviation of employment and real GDP.

3 'Cyclicality' is measured as the contemporaneous correlation between of employment and real GDP.

4 'Lead (lag)' is measured as the correlation between the leads (lags) in HP-filtered employment and real GDP.

5 'Persistence' is measured as the AR(1) coefficient in HP-filtered employment.

6 Bold figures indicate the largest correlation coefficient (in absolute value) in HP-filtered employment.

7 Data are at the quarterly frequency, unless otherwise indicated 1993:1 to 2002:4. All variables are de-seasonalized and de-trended. The alternative de-trending methods include the Hodrick-Prescott filter $(H P)$, log first-differencing $(F D)$ and fitting a quadratic time-trend polynomial $(T P)$. 
TABLE X

REAL WAGES

\begin{tabular}{|c|c|c|c|c|c|c|c|c|c|c|c|c|}
\hline & Bulgaria & Croatia & Czech Rep & Estonia & Hungary & Latvia & Lithuania & Poland & Romania & Russia & Slovakia & Slovenia \\
\hline \multicolumn{13}{|l|}{ Absolute Volatility $^{1}$} \\
\hline$H P$ & 7.73 & 2.18 & 2.29 & 2.51 & 2.36 & 3.51 & 5.92 & 1.33 & 7.46 & 11.56 & 3.53 & 1.10 \\
\hline$F D$ & 6.58 & 1.63 & 1.70 & 3.63 & 1.89 & 2.78 & 4.70 & 1.46 & 5.45 & 6.04 & 3.86 & 1.08 \\
\hline$T P$ & 7.67 & 1.88 & 2.73 & 2.54 & 2.06 & 3.58 & 6.33 & 1.26 & 8.11 & 11.87 & 3.93 & 1.19 \\
\hline \multicolumn{13}{|l|}{ Relative Volatility $^{2}$} \\
\hline$\stackrel{H P}{H}$ & 1.73 & 0.96 & 1.20 & 0.98 & 2.21 & 1.64 & 1.32 & 1.03 & 1.94 & 3.47 & 2.71 & 1.29 \\
\hline$F D$ & 1.73 & 0.72 & 1.25 & 1.81 & 2.28 & 1.40 & 0.93 & 1.88 & 1.74 & 2.69 & 3.33 & 0.95 \\
\hline$T P$ & 1.76 & 0.79 & 1.23 & 0.94 & 1.80 & 1.73 & 1.38 & 1.36 & 1.84 & 4.04 & 2.70 & 1.36 \\
\hline \multicolumn{13}{|l|}{ Cyclicality $^{3}$} \\
\hline$H P$ & 0.59 & 0.04 & 0.62 & 0.01 & 0.24 & 0.28 & 0.38 & 0.05 & 0.56 & 0.26 & 0.55 & 0.19 \\
\hline$F D$ & 0.30 & 0.26 & 0.16 & 0.02 & 0.29 & 0.07 & 0.15 & 0.13 & 0.19 & 0.31 & 0.08 & 0.38 \\
\hline$T P$ & 0.57 & 0.00 & 0.71 & -0.03 & 0.33 & 0.31 & 0.52 & -0.28 & 0.63 & 0.28 & 0.64 & 0.00 \\
\hline \multicolumn{13}{|l|}{ Leads and Lags ${ }^{4}$} \\
\hline-4 & -0.29 & -0.21 & 0.45 & -0.29 & 0.51 & -0.55 & -0.24 & 0.63 & 0.40 & -0.43 & 0.37 & -0.23 \\
\hline-3 & -0.30 & -0.13 & 0.52 & 0.19 & 0.65 & -0.37 & -0.16 & 0.52 & 0.55 & -0.37 & 0.44 & -0.02 \\
\hline-2 & -0.08 & -0.14 & 0.68 & 0.02 & 0.73 & 0.08 & 0.17 & 0.28 & 0.60 & -0.27 & 0.49 & -0.11 \\
\hline-1 & 0.29 & -0.07 & 0.63 & 0.03 & 0.63 & 0.35 & 0.35 & -0.01 & 0.70 & -0.05 & 0.54 & 0.07 \\
\hline+1 & 0.76 & -0.04 & 0.57 & -0.01 & 0.02 & 0.31 & 0.29 & -0.08 & 0.33 & 0.53 & 0.51 & -0.11 \\
\hline+2 & 0.70 & 0.03 & 0.49 & -0.15 & -0.11 & 0.46 & 0.42 & -0.17 & 0.05 & 0.63 & 0.53 & -0.01 \\
\hline+3 & 0.39 & 0.19 & 0.47 & -0.22 & -0.25 & 0.42 & 0.47 & -0.29 & -0.09 & 0.59 & 0.35 & -0.34 \\
\hline \multicolumn{12}{|l|}{ Persistence $^{5}$} & -0.23 \\
\hline & 0.65 & 0.76 & 0.75 & -0.02 & 0.77 & 0.68 & 0.72 & 0.36 & 0.74 & 0.86 & 0.42 & 0.54 \\
\hline
\end{tabular}

Notes: $\quad 1$ 'Absolute Volatility' is measured as the standard deviation of real wages.

2 'Relative Volatility' is measured as the ratio of the standard deviation of real wages and real GDP.

3 'Cyclicality' is measured as the contemporaneous correlation between of real wages and real GDP.

4 'Lead (lag)' is measured as the correlation between the leads (lags) in HP-filtered real wages and real GDP.

5 'Persistence' is measured as the AR(1) coefficient in HP-filtered real wages.

6 Bold figures indicate the largest correlation coefficient (in absolute value) in HP-filtered real wages.

7 Data are at the quarterly frequency, unless otherwise indicated 1993:1 to 2002:4. All variables are de-seasonalized and de-trended. The alternative de-trending methods include the Hodrick-Prescott filter $(H P), \log$ first-differencing $(F D)$ and fitting a quadratic time-trend polynomial $(T P)$. 
TABLE XI

PRODUCTIVITY

\begin{tabular}{|c|c|c|c|c|c|c|c|c|c|c|c|c|}
\hline & Bulgaria & Croatia & Czech Rep & Estonia & Hungary & Latvia & Lithuania & Poland & Romania & Russia & Slovakia & Slovenia \\
\hline \multicolumn{13}{|l|}{ Absolute Volatility $^{1}$} \\
\hline$H P$ & 7.00 & 4.00 & 1.51 & 2.27 & 2.67 & 3.64 & & 3.34 & 7.22 & 4.17 & 2.22 & 2.32 \\
\hline$F D$ & 6.91 & 3.66 & 1.35 & 2.15 & 1.89 & 3.72 & & 3.50 & 4.85 & 4.70 & 2.24 & 1.79 \\
\hline$T P$ & 6.93 & 3.83 & 1.63 & 2.46 & 2.75 & 3.73 & & 3.41 & 8.21 & 4.21 & 2.28 & 2.47 \\
\hline \multicolumn{13}{|l|}{ Relative Volatility $^{2}$} \\
\hline$H P$ & 1.57 & 1.75 & 0.79 & 0.89 & 2.51 & 1.70 & & 2.59 & 1.88 & 1.25 & 1.71 & 2.71 \\
\hline$F D$ & 1.82 & 1.62 & 1.11 & 1.13 & 2.27 & 1.87 & & 4.50 & 1.54 & 2.09 & 1.93 & 1.58 \\
\hline$T P$ & 1.59 & 1.60 & 0.68 & 0.84 & 2.40 & 1.80 & & 3.67 & 1.86 & 1.44 & 1.57 & 2.82 \\
\hline \multicolumn{13}{|l|}{ Cyclicality $^{3}$} \\
\hline$H P$ & 0.38 & 0.31 & 0.92 & 0.84 & 0.69 & 0.56 & & 0.62 & 0.73 & 0.33 & 0.05 & 0.24 \\
\hline$F D$ & 0.39 & 0.30 & 0.97 & 0.87 & 0.60 & 0.34 & & 0.45 & 0.38 & 0.51 & 0.12 & 0.13 \\
\hline$T P$ & 0.45 & 0.29 & 0.92 & 0.88 & 0.76 & 0.55 & & 0.68 & 0.79 & 0.37 & 0.03 & 0.14 \\
\hline \multicolumn{13}{|l|}{ Leads and Lags ${ }^{4}$} \\
\hline-4 & -0.09 & -0.32 & -0.14 & 0.23 & 0.04 & -0.21 & & -0.24 & 0.30 & -0.46 & 0.00 & -0.25 \\
\hline-3 & -0.00 & -0.19 & -0.11 & 0.18 & 0.22 & -0.12 & & 0.06 & 0.53 & -0.32 & -0.14 & -0.34 \\
\hline-2 & 0.09 & -0.16 & -0.02 & 0.20 & 0.40 & 0.05 & & 0.33 & 0.63 & -0.16 & -0.16 & -0.07 \\
\hline-1 & 0.13 & 0.05 & 0.14 & 0.13 & 0.57 & 0.44 & & 0.47 & 0.59 & 0.08 & -0.03 & 0.05 \\
\hline+1 & 0.30 & 0.25 & 0.10 & 0.04 & 0.49 & 0.52 & & 0.50 & 0.68 & 0.24 & -0.04 & 0.30 \\
\hline+2 & -0.10 & 0.34 & 0.05 & 0.01 & 0.31 & 0.29 & & 0.31 & 0.51 & 0.16 & -0.28 & 0.22 \\
\hline+3 & -0.53 & 0.32 & 0.05 & -0.06 & 0.14 & 0.01 & & 0.07 & 0.41 & 0.18 & -0.32 & 0.30 \\
\hline+4 & -0.76 & -0.05 & -0.01 & -0.05 & 0.06 & -0.22 & & -0.05 & 0.25 & 0.31 & -0.37 & 0.06 \\
\hline & 0.52 & 0.58 & 0.74 & 0.91 & 0.67 & 0.46 & & 0.45 & 0.78 & 0.40 & 0.51 & 0.71 \\
\hline
\end{tabular}

Notes: $\quad 1$ 'Absolute Volatility' is measured as the standard deviation of productivity.

2 'Relative Volatility' is measured as the ratio of the standard deviation of productivity and real GDP.

3 'Cyclicality' is measured as the contemporaneous correlation between of productivity and real GDP.

4 'Lead (lag)' is measured as the correlation between the leads (lags) in HP-filtered productivity and real GDP.

5 'Persistence' is measured as the AR(1) coefficient in HP-filtered productivity.

6 Bold figures indicate the largest correlation coefficient (in absolute value) in HP-filtered productivity.

7 Data are at the quarterly frequency, unless otherwise indicated 1993:1 to 2002:4. All variables are de-seasonalized and de-trended. The alternative de-trending methods include the Hodrick-Prescott filter $(H P)$, log first-differencing $(F D)$ and fitting a quadratic time-trend polynomial $(T P)$. 
TABLE XII

PRIVATE SECTOR CREDIT

\begin{tabular}{|c|c|c|c|c|c|c|c|c|c|c|c|c|}
\hline & Bulgaria & Croatia & Czech Rep & Estonia & Hungary & Latvia & Lithuania & Poland & Romania & Russia & Slovakia & Slovenia \\
\hline \multicolumn{13}{|l|}{ Absolute Volatility $^{1}$} \\
\hline$H P$ & 55.89 & 8.52 & 5.33 & 10.58 & 6.40 & 22.38 & 11.62 & 5.39 & 18.48 & 13.09 & 17.08 & 4.63 \\
\hline$F D$ & 39.75 & 5.21 & 4.71 & 6.22 & 4.30 & 12.79 & 7.02 & 2.58 & 10.05 & 9.46 & 10.49 & 2.51 \\
\hline$T P$ & 61.44 & 9.22 & 3.85 & 10.79 & 6.92 & 23.50 & 12.36 & 7.47 & 22.12 & 12.13 & 20.10 & 4.69 \\
\hline \multicolumn{13}{|l|}{ Relative Volatility $^{2}$} \\
\hline$H P$ & 12.52 & 3.73 & 2.79 & 4.15 & 6.00 & 10.45 & 2.59 & 4.18 & 4.81 & 3.93 & 13.14 & 5.41 \\
\hline$F D$ & 10.44 & 2.31 & 3.46 & 3.10 & 5.17 & 6.43 & 1.39 & 3.31 & 3.20 & 4.21 & 9.05 & 2.21 \\
\hline$T P$ & 14.08 & 3.85 & 1.73 & 4.01 & 6.04 & 11.39 & 2.69 & 8.04 & 5.02 & 4.14 & 13.81 & 5.34 \\
\hline \multicolumn{13}{|l|}{ Cyclicality $^{3}$} \\
\hline$H P$ & 0.22 & 0.53 & 0.27 & 0.35 & 0.60 & 0.40 & -0.23 & 0.73 & 0.68 & 0.08 & 0.45 & -0.12 \\
\hline$F D$ & 0.17 & 0.24 & 0.10 & 0.00 & 0.50 & 0.25 & 0.16 & 0.38 & 0.21 & -0.01 & 0.15 & -0.12 \\
\hline$T P$ & 0.25 & 0.58 & 0.33 & 0.46 & 0.71 & 0.34 & -0.28 & 0.20 & 0.76 & -0.13 & 0.40 & -0.12 \\
\hline \multicolumn{13}{|l|}{ Leads and Lags ${ }^{4}$} \\
\hline-4 & -0.58 & -0.35 & 0.17 & -0.18 & 0.35 & -0.49 & -0.68 & 0.40 & 0.14 & -0.24 & -0.14 & 0.05 \\
\hline-3 & -0.44 & -0.19 & 0.28 & -0.04 & 0.47 & -0.32 & -0.69 & 0.60 & 0.39 & -0.21 & 0.04 & 0.01 \\
\hline-2 & -0.16 & 0.08 & 0.28 & 0.11 & 0.58 & -0.14 & -0.44 & 0.68 & 0.52 & -0.18 & 0.09 & 0.00 \\
\hline-1 & -0.05 & 0.36 & 0.30 & 0.27 & 0.60 & 0.09 & -0.33 & 0.71 & 0.65 & -0.10 & 0.26 & -0.11 \\
\hline+1 & 0.38 & 0.60 & 0.23 & 0.54 & 0.39 & 0.61 & -0.22 & 0.71 & 0.65 & 0.34 & 0.56 & -0.07 \\
\hline+2 & 0.56 & 0.58 & 0.18 & 0.63 & 0.21 & 0.66 & -0.01 & 0.70 & 0.52 & 0.47 & 0.64 & 0.08 \\
\hline+3 & 0.63 & 0.48 & 0.13 & 0.53 & -0.02 & 0.70 & 0.25 & 0.61 & 0.36 & 0.55 & 0.67 & 0.19 \\
\hline \multicolumn{12}{|l|}{ Persistence $^{5}$} & 0.32 \\
\hline & 0.76 & 0.82 & 0.76 & 0.86 & 0.87 & 0.87 & 0.82 & 0.91 & 0.86 & 0.79 & 0.82 & 0.86 \\
\hline
\end{tabular}

Notes: $\quad 1$ 'Absolute Volatility' is measured as the standard deviation of private sector credit.

2 'Relative Volatility' is measured as the ratio of the standard deviation of private sector credit and real GDP.

3 'Cyclicality' is measured as the contemporaneous correlation between of private sector credit and real GDP.

4 'Lead (lag)' is measured as the correlation between the leads (lags) in HP-filtered private sector credit and real GDP.

5 'Persistence' is measured as the AR(1) coefficient in HP-filtered private sector credit.

6 Bold figures indicate the largest correlation coefficient (in absolute value) in HP-filtered private sector credit.

7 Data are at the quarterly frequency, unless otherwise indicated 1993:1 to 2002:4. All variables are de-seasonalized and de-trended. The alternative de-trending methods include the Hodrick-Prescott filter $(H P), \log$ first-differencing $(F D)$ and fitting a quadratic time-trend polynomial $(T P)$. 
TABLE XIII

M1

\begin{tabular}{|c|c|c|c|c|c|c|c|c|c|c|c|c|}
\hline & Bulgaria & Croatia & Czech Rep & Estonia & Hungary & Latvia & Lithuania & Poland & Romania & Russia & Slovakia & Slovenia \\
\hline \multicolumn{13}{|l|}{ Absolute Volatility $^{1}$} \\
\hline$H P$ & 42.18 & 8.95 & 9.96 & 6.78 & 3.49 & 6.56 & 11.79 & 5.58 & 6.81 & 13.11 & 7.63 & 4.72 \\
\hline$F D$ & 19.52 & 4.66 & 4.60 & 4.74 & 1.71 & 5.24 & 7.90 & 4.10 & 5.37 & 7.28 & 4.07 & 4.12 \\
\hline$T P$ & 44.60 & 10.03 & 13.39 & 7.16 & 4.54 & 6.64 & 12.90 & 5.61 & 7.28 & 15.73 & 9.56 & 4.45 \\
\hline \multicolumn{13}{|l|}{ Relative Volatility $^{2}$} \\
\hline$H P$ & 9.45 & 3.92 & 5.21 & 2.66 & 3.28 & 3.06 & 2.63 & 4.33 & 1.77 & 3.93 & 5.87 & 5.52 \\
\hline$F D$ & 5.13 & 2.07 & 3.38 & 2.36 & 2.06 & 2.63 & 1.57 & 5.27 & 1.71 & 3.24 & 3.51 & 3.62 \\
\hline$T P$ & 10.22 & 4.20 & 6.02 & 2.66 & 3.97 & 3.22 & 2.81 & 6.04 & 1.65 & 5.36 & 6.57 & 5.06 \\
\hline \multicolumn{13}{|l|}{ Cyclicality $^{3}$} \\
\hline$H P$ & -0.30 & 0.55 & 0.30 & 0.03 & 0.07 & 0.28 & -0.07 & 0.21 & 0.16 & 0.65 & 0.45 & 0.24 \\
\hline$F D$ & -0.08 & 0.15 & 0.19 & 0.04 & 0.24 & -0.03 & 0.04 & 0.27 & -0.03 & 0.27 & 0.43 & 0.42 \\
\hline$T P$ & -0.27 & 0.60 & 0.47 & 0.00 & 0.25 & 0.35 & -0.04 & -0.17 & 0.38 & 0.45 & 0.52 & 0.15 \\
\hline \multicolumn{13}{|l|}{ Leads and Lags ${ }^{4}$} \\
\hline-4 & 0.26 & 0.40 & 0.73 & 0.24 & 0.68 & -0.53 & -0.47 & 0.83 & 0.24 & -0.19 & 0.77 & 0.05 \\
\hline-2 & 0.13 & 0.65 & 0.57 & 0.30 & 0.57 & 0.03 & 0.10 & 0.67 & 0.21 & 0.30 & 0.60 & 0.13 \\
\hline-1 & -0.02 & 0.64 & 0.42 & 0.20 & 0.30 & 0.11 & 0.18 & 0.46 & 0.24 & 0.53 & 0.52 & 0.09 \\
\hline+1 & -0.60 & 0.44 & 0.24 & -0.07 & -0.10 & 0.62 & -0.16 & -0.06 & 0.13 & 0.67 & 0.19 & -0.08 \\
\hline+2 & -0.80 & 0.21 & 0.14 & -0.15 & -0.20 & 0.58 & 0.12 & -0.29 & 0.33 & 0.60 & 0.07 & 0.05 \\
\hline+3 & -0.82 & 0.07 & 0.02 & -0.29 & -0.43 & 0.51 & 0.24 & -0.44 & 0.53 & 0.51 & -0.13 & -0.14 \\
\hline \multicolumn{7}{|l|}{ Persistence $^{5}$} & 0.27 & -0.52 & 0.54 & 0.39 & -0.35 & -0.08 \\
\hline & 0.91 & 0.88 & 0.88 & 0.80 & 0.88 & 0.68 & 0.82 & 0.81 & 0.75 & 0.88 & 0.87 & 0.66 \\
\hline
\end{tabular}

Notes: $\quad 1$ 'Absolute Volatility' is measured as the standard deviation of M1.

2 'Relative Volatility' is measured as the ratio of the standard deviation of M1 and real GDP.

3 'Cyclicality' is measured as the contemporaneous correlation between of M1 and real GDP.

4 'Lead (lag)' is measured as the correlation between the leads (lags) in HP-filtered M1 and real GDP.

5 'Persistence' is measured as the AR(1) coefficient in HP-filtered M1.

6 Bold figures indicate the largest correlation coefficient (in absolute value) in HP-filtered M1.

7 Data are at the quarterly frequency, unless otherwise indicated 1993:1 to 2002:4. All variables are de-seasonalized and de-trended. The alternative de-trending methods include the Hodrick-Prescott filter $(H P), \log$ first-differencing $(F D)$ and fitting a quadratic time-trend polynomial $(T P)$. 
TABLE XIV

M2

\begin{tabular}{|c|c|c|c|c|c|c|c|c|c|c|c|c|}
\hline & Bulgaria & Croatia & Czech Rep & Estonia & Hungary & Latvia & Lithuania & Poland & Romania & Russia & Slovakia & Slovenia \\
\hline \multicolumn{13}{|l|}{ Absolute Volatility $^{1}$} \\
\hline$H P$ & 30.03 & 9.88 & 5.01 & 6.30 & 1.60 & 9.47 & 10.99 & 3.87 & 8.06 & 14.09 & 2.52 & 4.66 \\
\hline$F D$ & 16.35 & 4.59 & 2.97 & 4.67 & 1.21 & 5.77 & 6.16 & 3.06 & 5.90 & 5.42 & 2.08 & 2.87 \\
\hline$T P$ & 30.66 & 10.84 & 6.42 & 6.14 & 1.69 & 9.61 & 12.26 & 2.40 & 6.17 & 17.05 & 2.62 & 5.34 \\
\hline \multicolumn{13}{|l|}{ Relative Volatility $^{2}$} \\
\hline$H P$ & 6.73 & 4.33 & 2.62 & 2.47 & 1.50 & 4.42 & 2.45 & 3.00 & 2.10 & 4.23 & 1.94 & 5.45 \\
\hline$F D$ & 4.29 & 2.03 & 2.18 & 2.33 & 1.45 & 2.90 & 1.22 & 3.93 & 1.88 & 2.41 & 1.80 & 2.53 \\
\hline$T P$ & 7.03 & 4.53 & 2.88 & 2.28 & 1.48 & 4.66 & 2.67 & 2.59 & 1.40 & 5.81 & 1.80 & 6.09 \\
\hline \multicolumn{13}{|l|}{ Cyclicality $^{3}$} \\
\hline$H P$ & -0.48 & 0.51 & 0.75 & 0.13 & -0.43 & 0.35 & -0.24 & 0.50 & -0.44 & 0.61 & 0.18 & -0.04 \\
\hline$F D$ & -0.34 & 0.01 & 0.45 & 0.07 & -0.23 & 0.01 & 0.05 & 0.33 & -0.34 & 0.13 & 0.19 & 0.09 \\
\hline$T P$ & -0.45 & 0.57 & 0.79 & 0.17 & -0.29 & 0.33 & -0.25 & -0.04 & -0.23 & 0.33 & 0.21 & -0.25 \\
\hline \multicolumn{13}{|l|}{ Leads and Lags ${ }^{4}$} \\
\hline-4 & 0.22 & 0.29 & 0.60 & 0.12 & 0.36 & -0.56 & -0.47 & 0.49 & -0.00 & 0.01 & 0.65 & -0.23 \\
\hline-2 & 0.12 & 0.65 & 0.72 & 0.24 & -0.10 & 0.06 & -0.17 & 0.54 & -0.23 & 0.52 & 0.44 & -0.20 \\
\hline-1 & -0.11 & 0.65 & 0.74 & 0.22 & -0.33 & 0.24 & -0.07 & 0.49 & -0.40 & 0.64 & 0.34 & -0.10 \\
\hline+1 & -0.74 & 0.46 & 0.62 & 0.15 & -0.47 & 0.61 & -0.32 & 0.48 & -0.21 & 0.54 & 0.04 & -0.07 \\
\hline+2 & -0.84 & 0.39 & 0.41 & 0.17 & -0.42 & 0.66 & -0.17 & 0.50 & 0.02 & 0.46 & -0.05 & -0.04 \\
\hline+3 & -0.74 & 0.25 & 0.22 & 0.04 & -0.44 & 0.53 & 0.02 & 0.47 & 0.21 & 0.40 & -0.18 & 0.04 \\
\hline+4 & -0.53 & 0.04 & 0.06 & -0.27 & -0.53 & 0.29 & 0.15 & 0.35 & 0.35 & 0.31 & -0.28 & 0.09 \\
\hline & 0.87 & 0.91 & 0.87 & 0.78 & 0.78 & 0.81 & 0.88 & 0.85 & 0.86 & 0.92 & 0.70 & 0.89 \\
\hline
\end{tabular}

Notes: $\quad 1$ 'Absolute Volatility' is measured as the standard deviation of M2.

2 'Relative Volatility' is measured as the ratio of the standard deviation of M2 and real GDP.

3 'Cyclicality' is measured as the contemporaneous correlation between of M2 and real GDP.

4 'Lead (lag)' is measured as the correlation between the leads (lags) in HP-filtered M2 and real GDP.

5 'Persistence' is measured as the AR(1) coefficient in HP-filtered M2.

6 Bold figures indicate the largest correlation coefficient (in absolute value) in HP-filtered M2.

7 Data are at the quarterly frequency, unless otherwise indicated 1993:1 to 2002:4. All variables are de-seasonalized and de-trended. The alternative de-trending methods include the Hodrick-Prescott filter $(H P), \log$ first-differencing $(F D)$ and fitting a quadratic time-trend polynomial $(T P)$. 
TABLE XV

M1 VELOCITY

\begin{tabular}{|c|c|c|c|c|c|c|c|c|c|c|c|c|}
\hline & Bulgaria & Croatia & Czech Rep & Estonia & Hungary & Latvia & Lithuania & Poland & Romania & Russia & Slovakia & Slovenia \\
\hline \multicolumn{13}{|l|}{ Absolute Volatility $^{1}$} \\
\hline$H P$ & 18.53 & 8.29 & 7.44 & 5.36 & 3.22 & 6.39 & 7.07 & 5.71 & 12.75 & 12.00 & 7.55 & 4.84 \\
\hline$F D$ & 15.19 & 4.98 & 5.01 & 4.48 & 2.42 & 5.29 & 7.60 & 3.90 & 8.31 & 6.59 & 4.03 & 3.88 \\
\hline$T P$ & 19.59 & 9.22 & 7.04 & 5.47 & 2.68 & 6.59 & 7.27 & 6.12 & 14.88 & 12.86 & 9.12 & 5.03 \\
\hline \multicolumn{13}{|l|}{ Relative Volatility $^{2}$} \\
\hline$\stackrel{H P}{H}$ & 4.15 & 3.63 & 3.89 & 2.10 & 3.02 & 2.99 & 1.58 & 4.43 & 3.32 & 3.60 & 5.81 & 5.67 \\
\hline$F D$ & 3.99 & 2.21 & 3.68 & 2.23 & 2.91 & 2.66 & 1.51 & 5.01 & 2.65 & 2.93 & 3.48 & 3.41 \\
\hline$T P$ & 4.49 & 3.86 & 3.16 & 2.03 & 2.34 & 3.19 & 1.58 & 6.59 & 3.37 & 4.38 & 6.27 & 5.73 \\
\hline \multicolumn{13}{|l|}{ Cyclicality $^{3}$} \\
\hline$H P$ & 0.63 & 0.34 & 0.37 & -0.06 & 0.36 & 0.33 & -0.12 & -0.12 & 0.61 & 0.11 & 0.44 & 0.00 \\
\hline$F D$ & 0.48 & -0.30 & -0.09 & -0.27 & 0.04 & -0.17 & -0.16 & -0.09 & -0.07 & -0.02 & 0.18 & 0.16 \\
\hline$T P$ & 0.57 & 0.42 & 0.65 & -0.12 & 0.35 & 0.31 & -0.13 & -0.31 & 0.71 & 0.09 & 0.56 & 0.01 \\
\hline \multicolumn{13}{|l|}{ Leads and Lags ${ }^{4}$} \\
\hline-4 & 0.01 & 0.48 & 0.67 & 0.05 & 0.06 & -0.43 & -0.58 & 0.86 & 0.36 & -0.73 & 0.71 & 0.24 \\
\hline-3 & 0.08 & 0.64 & 0.68 & 0.13 & 0.11 & -0.22 & -0.56 & 0.79 & 0.65 & -0.66 & 0.71 & 0.26 \\
\hline-2 & 0.13 & 0.68 & 0.60 & 0.26 & 0.34 & 0.01 & 0.10 & 0.57 & 0.81 & -0.47 & 0.59 & 0.14 \\
\hline-1 & 0.32 & 0.58 & 0.49 & 0.20 & 0.27 & 0.15 & 0.12 & 0.23 & 0.77 & -0.20 & 0.53 & 0.03 \\
\hline+1 & 0.67 & 0.33 & 0.31 & -0.04 & 0.29 & 0.69 & -0.10 & -0.36 & 0.49 & 0.46 & 0.27 & -0.20 \\
\hline+2 & 0.40 & 0.16 & 0.22 & -0.04 & 0.26 & 0.68 & 0.46 & -0.49 & 0.38 & 0.60 & 0.17 & -0.08 \\
\hline+3 & -0.09 & 0.05 & 0.07 & -0.16 & 0.01 & 0.61 & 0.52 & -0.51 & 0.25 & 0.63 & -0.02 & -0.25 \\
\hline \multicolumn{12}{|l|}{ Persistence $^{5}$} & -0.11 \\
\hline & 0.67 & 0.83 & 0.83 & 0.64 & 0.72 & 0.68 & 0.43 & 0.77 & 0.79 & 0.86 & 0.87 & 0.69 \\
\hline
\end{tabular}

Notes: $\quad 1$ 'Absolute Volatility' is measured as the standard deviation of M1 velocity.

2 'Relative Volatility' is measured as the ratio of the standard deviation of M1 velocity and real GDP.

3 'Cyclicality' is measured as the contemporaneous correlation between of M1 velocity and real GDP.

4 'Lead (lag)' is measured as the correlation between the leads (lags) in HP-filtered M1 velocity and real GDP.

5 'Persistence' is measured as the AR(1) coefficient in HP-filtered M1 velocity.

6 Bold figures indicate the largest correlation coefficient (in absolute value) in HP-filtered M1 velocity.

7 Data are at the quarterly frequency, unless otherwise indicated 1993:1 to 2002:4. All variables are de-seasonalized and de-trended. The alternative de-trending methods include the Hodrick-Prescott filter $(H P)$, log first-differencing $(F D)$ and fitting a quadratic time-trend polynomial $(T P)$. 
TABLE XVI

M2 VELOCITY

\begin{tabular}{|c|c|c|c|c|c|c|c|c|c|c|c|c|}
\hline & Bulgaria & Croatia & Czech Rep & Estonia & Hungary & Latvia & Lithuania & Poland & Romania & Russia & Slovakia & Slovenia \\
\hline \multicolumn{13}{|l|}{ Absolute Volatility $^{1}$} \\
\hline$H P$ & 17.60 & 9.13 & 4.22 & 5.05 & 2.05 & 9.43 & 8.09 & 2.75 & 9.82 & 8.39 & 2.41 & 3.21 \\
\hline$F D$ & 13.10 & 5.15 & 2.65 & 4.34 & 1.80 & 5.96 & 7.21 & 2.48 & 6.80 & 5.77 & 2.27 & 2.38 \\
\hline$T P$ & 17.02 & 10.06 & 4.76 & 5.20 & 1.71 & 9.38 & 8.58 & 2.75 & 10.82 & 8.73 & 2.54 & 3.67 \\
\hline \multicolumn{13}{|l|}{ Relative Volatility $^{2}$} \\
\hline$H P$ & 3.94 & 4.00 & 2.21 & 1.98 & 1.92 & 4.40 & 1.81 & 2.13 & 2.55 & 2.52 & 1.85 & 3.76 \\
\hline$F D$ & 3.44 & 2.28 & 1.95 & 2.17 & 2.17 & 3.00 & 1.43 & 3.18 & 2.16 & 2.57 & 1.96 & 2.09 \\
\hline$T P$ & 3.90 & 4.21 & 2.14 & 1.93 & 1.49 & 4.54 & 1.87 & 2.97 & 2.45 & 2.98 & 1.75 & 4.18 \\
\hline \multicolumn{13}{|l|}{ Cyclicality $^{3}$} \\
\hline$H P$ & 0.56 & 0.32 & 0.60 & 0.07 & -0.22 & 0.38 & -0.33 & -0.12 & 0.43 & 0.10 & 0.17 & -0.40 \\
\hline$F D$ & 0.25 & -0.42 & 0.00 & -0.24 & -0.32 & -0.12 & -0.17 & -0.19 & -0.32 & -0.24 & -0.28 & -0.36 \\
\hline$T P$ & 0.53 & 0.40 & 0.69 & 0.07 & -0.41 & 0.31 & -0.42 & -0.39 & 0.60 & -0.03 & 0.27 & -0.54 \\
\hline \multicolumn{13}{|l|}{ Leads and Lags ${ }^{4}$} \\
\hline-4 & -0.21 & 0.35 & 0.53 & -0.13 & 0.05 & -0.49 & -0.45 & 0.15 & 0.15 & -0.60 & 0.40 & -0.04 \\
\hline-3 & -0.13 & 0.54 & 0.67 & -0.06 & -0.02 & -0.23 & -0.64 & 0.14 & 0.54 & -0.46 & 0.45 & -0.23 \\
\hline-2 & 0.02 & 0.68 & 0.73 & 0.17 & -0.08 & 0.05 & -0.28 & 0.02 & 0.71 & -0.30 & 0.38 & -0.26 \\
\hline-1 & 0.20 & 0.60 & 0.68 & 0.22 & -0.25 & 0.27 & -0.27 & -0.15 & 0.58 & -0.13 & 0.35 & -0.22 \\
\hline+1 & 0.83 & 0.37 & 0.51 & 0.21 & -0.12 & 0.66 & -0.29 & -0.04 & 0.43 & 0.43 & 0.28 & -0.30 \\
\hline+2 & 0.85 & 0.37 & 0.35 & 0.30 & 0.09 & 0.71 & 0.06 & 0.22 & 0.35 & 0.60 & 0.26 & -0.27 \\
\hline+3 & 0.60 & 0.25 & 0.15 & 0.22 & 0.16 & 0.58 & 0.18 & 0.44 & 0.16 & 0.69 & 0.18 & -0.15 \\
\hline \multirow{2}{*}{$\begin{array}{r}+4 \\
\text { Persistence }^{5}\end{array}$} & 0.38 & 0.04 & -0.09 & -0.01 & 0.02 & 0.37 & 0.12 & 0.56 & -0.00 & 0.61 & -0.01 & 0.06 \\
\hline & 0.75 & 0.86 & 0.81 & 0.61 & 0.61 & 0.82 & 0.63 & 0.59 & 0.77 & 0.78 & 0.57 & 0.76 \\
\hline
\end{tabular}

Notes: $\quad 1$ 'Absolute Volatility' is measured as the standard deviation of M2 velocity.

2 'Relative Volatility' is measured as the ratio of the standard deviation of M2 velocity and real GDP.

3 'Cyclicality' is measured as the contemporaneous correlation between of M2 velocity and real GDP.

4 'Lead (lag)' is measured as the correlation between the leads (lags) in HP-filtered M2 velocity and real GDP.

5 'Persistence' is measured as the AR(1) coefficient in HP-filtered M2 velocity.

6 Bold figures indicate the largest correlation coefficient (in absolute value) in HP-filtered M2 velocity.

7 Data are at the quarterly frequency, unless otherwise indicated 1993:1 to 2002:4. All variables are de-seasonalized and de-trended. The alternative de-trending methods include the Hodrick-Prescott filter $(H P), \log$ first-differencing $(F D)$ and fitting a quadratic time-trend polynomial $(T P)$. 
TABLE XVII

CPI

\begin{tabular}{|c|c|c|c|c|c|c|c|c|c|c|c|c|}
\hline & Bulgaria & Croatia & Czech Rep & Estonia & Hungary & Latvia & Lithuania & Poland & Romania & Russia & Slovakia & Slovenia \\
\hline \multicolumn{13}{|l|}{ Absolute Volatility $^{1}$} \\
\hline$H P$ & 48.85 & 0.94 & 1.58 & 5.59 & 2.30 & 4.71 & 9.80 & 2.66 & 16.63 & 18.98 & 2.34 & 2.29 \\
\hline$F D$ & 28.33 & 0.76 & 1.09 & 3.26 & 1.65 & 2.90 & 7.40 & 1.55 & 10.11 & 7.73 & 1.29 & 1.24 \\
\hline$T P$ & 48.74 & 0.96 & 1.41 & 5.74 & 1.45 & 4.41 & 10.20 & 2.40 & 16.47 & 21.66 & 2.53 & 2.63 \\
\hline \multicolumn{13}{|l|}{ Relative Volatility $^{2}$} \\
\hline$H P$ & 10.94 & 0.41 & 0.82 & 2.19 & 2.16 & 2.20 & 2.19 & 2.07 & 4.33 & 5.69 & 1.80 & 2.68 \\
\hline$F D$ & 7.44 & 0.34 & 0.80 & 1.62 & 1.99 & 1.46 & 1.47 & 1.99 & 3.22 & 3.44 & 1.11 & 1.09 \\
\hline$T P$ & 11.18 & 0.40 & 0.63 & 2.13 & 1.27 & 2.14 & 2.22 & 2.58 & 3.73 & 7.38 & 1.74 & 2.99 \\
\hline \multicolumn{13}{|l|}{ Cyclicality $^{3}$} \\
\hline$H P$ & -0.59 & -0.15 & -0.20 & -0.37 & -0.32 & -0.52 & -0.46 & 0.18 & -0.73 & 0.34 & -0.53 & 0.12 \\
\hline$F D$ & -0.45 & -0.12 & -0.02 & -0.19 & -0.32 & -0.42 & -0.47 & 0.45 & -0.36 & -0.02 & -0.10 & -0.03 \\
\hline$T P$ & -0.56 & -0.24 & -0.33 & -0.35 & -0.65 & -0.41 & -0.40 & 0.02 & -0.78 & 0.14 & -0.63 & -0.09 \\
\hline \multicolumn{13}{|l|}{ Leads and Lags 4} \\
\hline-4 & 0.23 & -0.32 & -0.45 & 0.29 & -0.47 & -0.17 & -0.32 & -0.05 & -0.22 & 0.25 & 0.07 & -0.35 \\
\hline-3 & 0.15 & -0.29 & -0.44 & 0.09 & -0.59 & -0.31 & 0.07 & -0.16 & -0.50 & 0.39 & -0.12 & -0.35 \\
\hline-2 & 0.03 & -0.30 & -0.41 & -0.09 & -0.61 & -0.11 & 0.00 & -0.10 & -0.68 & 0.49 & -0.20 & -0.15 \\
\hline-1 & -0.20 & -0.23 & -0.28 & -0.27 & -0.48 & -0.32 & 0.00 & 0.05 & -0.78 & 0.48 & -0.35 & 0.06 \\
\hline+1 & -0.81 & 0.00 & -0.07 & -0.38 & -0.24 & -0.50 & -0.35 & 0.16 & -0.55 & 0.16 & -0.62 & 0.22 \\
\hline+2 & -0.85 & 0.10 & -0.05 & -0.35 & -0.24 & -0.43 & -0.39 & 0.08 & -0.31 & 0.05 & -0.64 & 0.21 \\
\hline+3 & -0.67 & 0.13 & 0.08 & -0.29 & -0.21 & -0.34 & -0.29 & -0.06 & -0.09 & -0.03 & -0.69 & 0.27 \\
\hline \multicolumn{8}{|l|}{ Persistence $^{5}$} & -0.21 & 0.09 & -0.05 & -0.51 & 0.17 \\
\hline & 0.86 & 0.68 & 0.85 & 0.95 & 0.92 & 0.94 & 0.85 & 0.95 & 0.84 & 0.91 & 0.86 & 0.92 \\
\hline
\end{tabular}

Notes: $\quad 1$ 'Absolute Volatility' is measured as the standard deviation of the CPI.

2 'Relative Volatility' is measured as the ratio of the standard deviation of the CPI and real GDP.

3 'Cyclicality' is measured as the contemporaneous correlation between of the CPI and real GDP.

4 'Lead (lag)' is measured as the correlation between the leads (lags) in HP-filtered the CPI and real GDP.

5 'Persistence' is measured as the AR(1) coefficient in HP-filtered the CPI.

6 Bold figures indicate the largest correlation coefficient (in absolute value) in HP-filtered the CPI.

7 Data are at the quarterly frequency, unless otherwise indicated 1993:1 to 2002:4. All variables are de-seasonalized and de-trended. The alternative de-trending methods include the Hodrick-Prescott filter $(H P), \log$ first-differencing $(F D)$ and fitting a quadratic time-trend polynomial $(T P)$. 
TABLE XVIII

INFLATION

\begin{tabular}{|c|c|c|c|c|c|c|c|c|c|c|c|c|}
\hline & Bulgaria & Croatia & Czech Rep & Estonia & Hungary & Latvia & Lithuania & Poland & Romania & Russia & Slovakia & Slovenia \\
\hline \multicolumn{13}{|l|}{ Absolute Volatility $^{1}$} \\
\hline$H P$ & 25.40 & 0.73 & 0.84 & 1.40 & 0.84 & 1.29 & 4.55 & 0.73 & 7.94 & 7.51 & 1.10 & 0.76 \\
\hline$F D$ & 30.06 & 1.12 & 1.10 & 1.31 & 0.84 & 1.81 & 5.50 & 0.89 & 7.14 & 5.84 & 1.55 & 1.00 \\
\hline$T P$ & 26.10 & 0.73 & 0.85 & 1.45 & 0.91 & 1.28 & 4.65 & 0.75 & 8.42 & 8.39 & 1.19 & 0.78 \\
\hline \multicolumn{13}{|l|}{ Relative Volatility $^{2}$} \\
\hline$H P$ & 5.69 & 0.32 & 0.44 & 0.55 & 0.79 & 0.60 & 1.02 & 0.56 & 2.07 & 2.25 & 0.84 & 0.89 \\
\hline$F D$ & 7.90 & 0.49 & 0.81 & 0.65 & 1.01 & 0.91 & 1.09 & 1.14 & 2.27 & 2.60 & 1.34 & 0.88 \\
\hline$T P$ & 5.98 & 0.31 & 0.38 & 0.54 & 0.80 & 0.62 & 1.01 & 0.80 & 1.91 & 2.86 & 0.82 & 0.89 \\
\hline \multicolumn{13}{|l|}{ Cyclicality $^{3}$} \\
\hline$H P$ & -0.73 & 0.07 & 0.15 & -0.04 & 0.41 & -0.15 & 0.17 & 0.38 & 0.13 & -0.49 & -0.27 & 0.09 \\
\hline$F D$ & -0.63 & -0.05 & -0.19 & 0.28 & 0.00 & -0.12 & -0.22 & 0.21 & -0.00 & -0.36 & -0.09 & -0.13 \\
\hline$T P$ & -0.74 & 0.05 & 0.17 & -0.14 & 0.25 & -0.26 & 0.17 & 0.55 & 0.10 & -0.48 & -0.36 & 0.19 \\
\hline \multicolumn{13}{|l|}{ Leads and Lags 4} \\
\hline-4 & 0.10 & -0.19 & -0.21 & -0.20 & -0.55 & -0.03 & 0.48 & -0.44 & -0.57 & 0.14 & -0.39 & 0.09 \\
\hline-3 & -0.14 & 0.04 & 0.03 & -0.34 & -0.30 & 0.04 & 0.31 & -0.23 & -0.40 & 0.08 & -0.38 & -0.01 \\
\hline-2 & -0.18 & 0.01 & 0.10 & -0.41 & 0.04 & 0.22 & -0.23 & 0.10 & -0.22 & 0.02 & -0.33 & 0.40 \\
\hline-1 & -0.44 & 0.04 & 0.25 & -0.25 & 0.36 & -0.27 & 0.04 & 0.35 & -0.14 & -0.18 & -0.26 & 0.14 \\
\hline+1 & -0.41 & 0.17 & 0.26 & 0.01 & 0.39 & 0.34 & 0.46 & 0.25 & 0.38 & -0.63 & -0.17 & 0.26 \\
\hline+2 & -0.06 & 0.00 & 0.05 & 0.13 & 0.13 & 0.20 & -0.29 & -0.04 & 0.47 & -0.47 & -0.02 & 0.01 \\
\hline+3 & 0.35 & -0.07 & 0.23 & 0.16 & 0.36 & 0.10 & 0.11 & -0.05 & 0.38 & -0.28 & -0.13 & 0.11 \\
\hline \multicolumn{12}{|l|}{ Persistence $^{5}$} & -0.19 \\
\hline & 0.32 & -0.12 & 0.15 & 0.58 & 0.24 & -0.11 & 0.24 & 0.35 & 0.61 & 0.67 & 0.03 & 0.17 \\
\hline
\end{tabular}

Notes: $\quad 1$ 'Absolute Volatility' is measured as the standard deviation of inflation.

2 'Relative Volatility' is measured as the ratio of the standard deviation of inflation and real GDP.

3 'Cyclicality' is measured as the contemporaneous correlation between of inflation and real GDP.

4 'Lead (lag)' is measured as the correlation between the leads (lags) in HP-filtered inflation and real GDP.

5 'Persistence' is measured as the AR(1) coefficient in HP-filtered inflation.

6 Bold figures indicate the largest correlation coefficient (in absolute value) in HP-filtered inflation.

7 Data are at the quarterly frequency, unless otherwise indicated 1993:1 to 2002:4. All variables are de-seasonalized and de-trended. The alternative de-trending methods include the Hodrick-Prescott filter $(H P), \log$ first-differencing $(F D)$ and fitting a quadratic time-trend polynomial $(T P)$. 
TABLE XIX

NOMINAL EFFECTIVE EXCHANGE RATE

\begin{tabular}{|c|c|c|c|c|c|c|c|c|c|c|c|c|}
\hline & Bulgaria & Croatia & Czech Rep & Estonia & Hungary & Latvia & Lithuania & Poland & Romania & Russia & Slovakia & Slovenia \\
\hline \multicolumn{13}{|l|}{ Absolute Volatility ${ }^{1}$} \\
\hline$H P$ & 47.41 & 2.32 & 3.16 & 6.53 & 3.87 & & 13.57 & 4.03 & 12.19 & 24.49 & 3.54 & 2.61 \\
\hline$F D$ & 26.01 & 1.72 & 2.45 & 3.69 & 2.91 & & 8.21 & 3.00 & 9.25 & 14.06 & 2.60 & 2.21 \\
\hline$T P$ & 48.14 & 2.52 & 3.42 & 6.63 & 2.49 & & 13.32 & 3.86 & 11.55 & 26.23 & 3.76 & 2.65 \\
\hline \multicolumn{13}{|l|}{ Relative Volatility $^{2}$} \\
\hline$H P$ & 10.62 & 1.01 & 1.65 & 2.56 & 3.63 & & 3.03 & 3.13 & 3.17 & 7.35 & 2.72 & 3.06 \\
\hline$F D$ & 6.83 & 0.76 & 1.80 & 1.84 & 3.50 & & 1.63 & 3.86 & 2.95 & 6.26 & 2.25 & 1.94 \\
\hline$T P$ & 11.04 & 1.05 & 1.54 & 2.46 & 2.18 & & 2.90 & 4.16 & 2.62 & 8.94 & 2.58 & 3.01 \\
\hline \multicolumn{13}{|l|}{ Cyclicality $^{3}$} \\
\hline$H P$ & 0.66 & 0.52 & 0.14 & -0.70 & -0.07 & & -0.35 & -0.34 & 0.52 & 0.05 & 0.65 & -0.13 \\
\hline$F D$ & 0.50 & 0.19 & -0.20 & -0.23 & 0.27 & & -0.13 & -0.30 & 0.26 & 0.01 & 0.51 & 0.01 \\
\hline$T P$ & 0.64 & 0.57 & 0.34 & -0.72 & -0.23 & & -0.41 & -0.38 & 0.58 & 0.01 & 0.65 & -0.11 \\
\hline \multicolumn{13}{|l|}{ Leads and Lags 4} \\
\hline-4 & -0.27 & 0.35 & 0.38 & -0.07 & 0.45 & & -0.35 & -0.22 & 0.13 & -0.56 & 0.12 & -0.02 \\
\hline-3 & -0.13 & 0.65 & 0.31 & -0.31 & 0.44 & & -0.69 & -0.36 & 0.35 & -0.54 & 0.35 & 0.07 \\
\hline-2 & 0.04 & 0.48 & 0.15 & -0.49 & 0.41 & & -0.59 & -0.46 & 0.55 & -0.48 & 0.37 & -0.14 \\
\hline-1 & 0.31 & 0.42 & 0.12 & -0.65 & 0.23 & & -0.39 & -0.39 & 0.61 & -0.29 & 0.46 & -0.17 \\
\hline+1 & 0.83 & 0.55 & 0.27 & -0.65 & -0.30 & & -0.46 & -0.20 & 0.25 & 0.41 & 0.49 & -0.08 \\
\hline+2 & 0.82 & 0.30 & 0.40 & -0.53 & -0.32 & & -0.40 & -0.07 & 0.05 & 0.59 & 0.42 & -0.04 \\
\hline+3 & 0.62 & 0.02 & 0.28 & -0.32 & -0.27 & & 0.02 & 0.07 & -0.06 & 0.60 & 0.24 & -0.04 \\
\hline \multirow{2}{*}{$\begin{array}{r}+4 \\
\text { Persistence }^{5}\end{array}$} & 0.39 & -0.20 & 0.14 & 0.02 & -0.14 & & 0.21 & 0.18 & -0.09 & 0.48 & 0.10 & -0.03 \\
\hline & 0.87 & 0.74 & 0.72 & 0.86 & 0.88 & & 0.84 & 0.80 & 0.73 & 0.84 & 0.73 & 0.61 \\
\hline
\end{tabular}

Notes: $\quad 1$ 'Absolute Volatility' is measured as the standard deviation of the nominal effective exchange rate.

2 'Relative Volatility' is measured as the ratio of the standard deviation of nominal effective exchange rate and real GDP.

3 'Cyclicality' is measured as the contemporaneous correlation between of nominal effective exchange rate and real GDP.

4 'Lead (lag)' is measured as the correlation between the leads (lags) in HP-filtered nominal effective exchange rate and real GDP.

5 'Persistence' is measured as the AR(1) coefficient in HP-filtered nominal effective exchange rate.

6 Bold figures indicate the largest correlation coefficient (in absolute value) in HP-filtered nominal effective exchange rate.

7 Data are at the quarterly frequency, unless otherwise indicated 1993:1 to 2002:4. All variables are de-seasonalized and de-trended. The alternative de-trending methods include the Hodrick-Prescott filter $(H P), \log$ first-differencing $(F D)$ and fitting a quadratic time-trend polynomial $(T P)$. 
TABLE XX

REAL EFFECTIVE EXCHANGE RATE

\begin{tabular}{|c|c|c|c|c|c|c|c|c|c|c|c|c|}
\hline & Bulgaria & Croatia & Czech Rep & Estonia & Hungary & Latvia & Lithuania & Poland & Romania & Russia & Slovakia & Slovenia \\
\hline \multicolumn{13}{|l|}{ Absolute Volatility $^{1}$} \\
\hline$H P$ & 8.59 & 1.99 & 3.12 & 4.54 & 2.91 & 6.01 & 6.03 & 4.11 & 9.27 & 16.00 & 3.28 & 2.90 \\
\hline$F D$ & 7.38 & 1.83 & 2.47 & 3.21 & 1.89 & 3.64 & 6.16 & 3.04 & 6.23 & 9.48 & 2.82 & 2.30 \\
\hline$T P$ & 8.84 & 2.01 & 3.35 & 4.43 & 2.88 & 6.80 & 6.97 & 4.30 & 9.76 & 18.17 & 3.31 & 3.07 \\
\hline \multicolumn{13}{|l|}{ Relative Volatility $^{2}$} \\
\hline$H P$ & 1.92 & 0.87 & 1.63 & 1.78 & 2.73 & 2.81 & 1.35 & 3.19 & 2.41 & 4.80 & 2.52 & 3.39 \\
\hline$F D$ & 1.94 & 0.81 & 1.81 & 1.60 & 2.27 & 1.83 & 1.22 & 3.91 & 1.98 & 4.22 & 2.44 & 2.03 \\
\hline$T P$ & 2.03 & 0.84 & 1.51 & 1.65 & 2.52 & 3.30 & 1.52 & 4.63 & 2.21 & 6.19 & 2.27 & 3.49 \\
\hline \multicolumn{13}{|l|}{ Cyclicality $^{3}$} \\
\hline$H P$ & 0.59 & 0.33 & -0.05 & -0.27 & -0.39 & -0.22 & -0.10 & -0.22 & -0.59 & 0.19 & 0.17 & 0.01 \\
\hline$F D$ & 0.52 & 0.05 & -0.26 & -0.14 & 0.09 & -0.17 & -0.08 & -0.09 & -0.12 & 0.04 & 0.33 & 0.02 \\
\hline$T P$ & 0.61 & 0.37 & 0.10 & -0.17 & -0.52 & -0.09 & -0.04 & -0.34 & -0.65 & 0.10 & 0.13 & -0.10 \\
\hline \multicolumn{13}{|l|}{ Leads and Lags ${ }^{4}$} \\
\hline-4 & -0.06 & 0.24 & -0.08 & 0.17 & 0.19 & -0.28 & -0.26 & -0.20 & -0.24 & -0.60 & 0.14 & -0.24 \\
\hline-3 & 0.32 & 0.53 & -0.14 & 0.10 & 0.08 & -0.33 & -0.09 & -0.41 & -0.42 & -0.52 & 0.23 & -0.14 \\
\hline-2 & 0.51 & 0.27 & -0.22 & -0.10 & 0.00 & -0.37 & -0.53 & -0.51 & -0.44 & -0.40 & 0.15 & -0.15 \\
\hline-1 & 0.73 & 0.17 & -0.15 & -0.23 & -0.14 & -0.30 & -0.19 & -0.36 & -0.52 & -0.17 & 0.12 & -0.07 \\
\hline+1 & 0.09 & 0.45 & 0.18 & -0.35 & -0.58 & -0.05 & 0.35 & -0.10 & -0.63 & 0.55 & -0.06 & 0.10 \\
\hline+2 & -0.32 & 0.32 & 0.37 & -0.31 & -0.60 & 0.14 & 0.09 & -0.03 & -0.48 & 0.73 & -0.12 & 0.10 \\
\hline+3 & -0.55 & 0.04 & 0.36 & -0.16 & -0.50 & 0.19 & 0.41 & 0.03 & -0.23 & 0.70 & -0.34 & 0.12 \\
\hline & \multicolumn{2}{|c|}{ Persistence $^{5}$} & & 0.16 & -0.29 & 0.23 & 0.36 & 0.05 & 0.00 & 0.57 & -0.34 & 0.04 \\
\hline & 0.64 & 0.59 & 0.70 & 0.76 & 0.80 & 0.83 & 0.44 & 0.75 & 0.78 & 0.84 & 0.64 & 0.69 \\
\hline
\end{tabular}

Notes: $\quad 1$ 'Absolute Volatility' is measured as the standard deviation of the real effective exchange rate.

2 'Relative Volatility' is measured as the ratio of the standard deviation of the real effective exchange rate and real GDP.

3 'Cyclicality' is measured as the contemporaneous correlation between of the real effective exchange rate and real GDP.

4 'Lead (lag)' is measured as the correlation between the leads (lags) in HP-filtered the real effective exchange rate and real GDP.

5 'Persistence' is measured as the AR(1) coefficient in HP-filtered the real effective exchange rate.

6 Bold figures indicate the largest correlation coefficient (in absolute value) in HP-filtered the real effective exchange rate.

7 Data are at the quarterly frequency, unless otherwise indicated 1993:1 to 2002:4. All variables are de-seasonalized and de-trended. The alternative de-trending methods include the Hodrick-Prescott filter $(H P), \log$ first-differencing $(F D)$ and fitting a quadratic time-trend polynomial $(T P)$. 
TABLE AI

\begin{tabular}{|c|c|c|c|c|c|}
\hline Bulgaria & Croatia & Czech Rep & Estonia & Hungary & Latvia \\
\hline
\end{tabular}

Lithuania

Poland

Romania

Russia

SO, 1995:1 - IFS, 1997:1 2002:4 2002:4 2002:4

WIIW

\section{Consumption}

$$
\text { SO }
$$

N/A IFS

SO

IFS

IFS

IFS

IFS

SO

IFS

\section{Investment}

Government

N/A IFS

SO

$$
\text { IFS }
$$

$$
\text { IFS }
$$

$$
\text { IFS }
$$

$$
\text { IFS }
$$

$$
\text { IFS }
$$

IFS, 1995:1 -

Imports

$$
\text { IFS }
$$

$$
\text { IFS }
$$

IFS

IFS
IFS, 1993:1 -
2002:1

IFS 2002:1

$$
\text { IFS }
$$$$
\text { IFS, 1995:1 - }
$$

Employment

N/A N/A SO
2002:4

IFS, 1993:3 -

IFS IFS

IFS

IFS

CB

$$
\text { IFS }
$$

CB, 1993:2 2002:4

IFS

N/A

Nominal Effective

Exchange Rate

Real Effective

$\begin{array}{lll} & \text { IFS } & \text { IFS } \\ \text { IFS } & \text { IFS } & \text { IFS }\end{array}$

\section{N/A}

CB, 1993:4 - CB, 1993:2 -

IFS IFS

$\begin{array}{ccr}\text { IFS } & \text { IFS } & \text { IFS } \\ 1994: 1 & 1995: 1 & 1994: 1\end{array}$

CB

IFS 2002:4

$\begin{array}{cr}\text { IFS } & \text { IFS } \\ 1995: 1-1994: 1\end{array}$

2002:4

$1995: 1-$
$2002: 4$

$1993: 1-$
$2002: 4$ 2002:4 2002:4 2002:4

IFS

IFS

IFS

IFS IFS

CB

Notes

2002:4 2002:4
2002:4 2002:4

IFS

IFS

i. Unless otherwise indicated, the default sample period is determined by the availability of GDP data, as shown in the last row of the table.

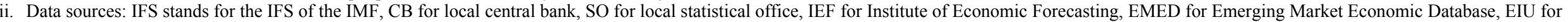
Economic Intelligence Unit, WIIW for WIIW dataset. N/A indicates missing or inadequately short series. 